\title{
Calibration of Microscopic Traffic Flow Simulation Models considering Subsets of Links and Parameters
}

\author{
Alexander Paz $\mathbb{D}^{1},{ }^{1}$ Kul Shrestha $\mathbb{D}^{2},{ }^{2}$ Cristian Arteaga $\mathbb{D D}^{3}$ and Douglas Baker ${ }^{4}{ }^{4}$ \\ ${ }^{1}$ School of Civil Engineering, Queensland University of Technology, Brisbane 4001, Australia \\ ${ }^{2}$ NOVA Geotechnical \& Inspection Services, Las Vegas, NV 89118, USA \\ ${ }^{3}$ Department of Civil and Environmental Engineering and Construction, University of Nevada, Las Vegas 89154, NV, USA \\ ${ }^{4}$ School of Built Environment, Queensland University of Technology, Brisbane 4001, Australia \\ Correspondence should be addressed to Alexander Paz; alexander.paz@qut.edu.au
}

Received 12 June 2020; Revised 10 October 2020; Accepted 19 October 2020; Published 31 October 2020

Academic Editor: Vittorio Astarita

Copyright (c 2020 Alexander Paz et al. This is an open access article distributed under the Creative Commons Attribution License, which permits unrestricted use, distribution, and reproduction in any medium, provided the original work is properly cited.

\begin{abstract}
This study proposes a methodology for the calibration of microscopic traffic flow simulation models by enabling simultaneous selection of traffic links and associated parameters. The analyst selects any number and combination of links and model parameters for calibration. Most calibration methods consider the entire network and use ad hoc approaches without enabling a specific selection of location and associated parameters. In practice, only a subset of links and parameters is used for calibration based on several factors such as expert knowledge of the system or constraints imposed by local governance. In this study, the calibration problem for the simultaneous selection of links and parameters was formulated using a mathematical programming approach. The proposed methodology is capable of calibrating model parameters considering multiple time periods and performance measures simultaneously. Traffic volume and speed are the performance measures used in this study, and the methodology is developed without considering the characteristics of a specific traffic flow model. A genetic algorithm was implemented to find a solution to the proposed mathematical program. In the experiments, two traffic models were calibrated: the first set of experiments included selection of links only, while all associated parameters were considered for calibration. The second set of experiments considered simultaneous selection of links and parameters. The implications of these experiments indicate that the models were calibrated successfully subject to selection of a minimum number of links. As expected, the more links and parameters that are used for calibration, the more time it takes to find a solution, but the overall results are better. All parameter values were reasonable and within constraints after successful calibration.
\end{abstract}

\section{Introduction}

Microscopic traffic flow simulation is increasingly being used to analyze complex scenarios for a broad range of objectives. One of the most important and challenging aspects for obtaining meaningful results is calibration, which involves adjusting the model parameters to enhance the ability of the model to generate local traffic conditions [1-3]. Existing calibration approaches propose various optimization algorithms and varying sets of calibration parameters. Sequential as well as simultaneous calibration of model parameters are proposed in the literature.

The calibration approach provided by the Federal Highway Administration (FHWA) in Traffic Analysis
Toolbox Volume IV suggests a sequential process of calibrating the capacity at key bottlenecks, traffic volumes, and system performance [2]. Using this approach, model parameters are adjusted by modifying global parameters first, then link parameters, and finally route choice parameters. $\mathrm{Ma}$ et al. [4] used a sequential approach to calibrate global and local parameters separately. Jha et al. [5] calibrated driver-behavior parameters separately from other parameters, such as route choice factors and origin-destination $(\mathrm{O}$ D) flows. Paz et al. [3,6] used an iterative approach where one group of parameters was calibrated, while others remained fixed. Issues associated with the use of a sequential calibration process include difficulty to achieve convergence and stable solutions [6]. 
Many mathematical programming formulations have been proposed to characterize and solve the problem of calibrating simulation-based traffic flow models. A simplex algorithm was proposed to calibrate microscopic traffic flow simulation models using intelligent transportation system data [7]. The proposed algorithm was very effective for congested conditions compared to simple manual calibration techniques. However, this effectiveness decreased as congestion decreased. The proposed approach considers only a single objective to minimize the difference between observed and estimated volume. In practice, multiple objectives are likely to be required.

Various genetic algorithms (GAs) have been proposed to calibrate microscopic simulation models $[4,5,8-14]$ with successful results and relatively faster convergence. Yang et al. [15] proposed an orthogonal genetic algorithm (OGA) that provided superior results when compared to a GA; however, the number of calibrated parameters was few. In contrast, GA was found to converge relatively quickly for simulation models with many parameters [10]. Simultaneous perturbation stochastic approximation (SPSA) algorithms have also been widely used to calibrate microscopic simulation models [4, 16-19]. SPSA was found to provide a similar level of accuracy, fewer iterations, and less computation time than GAs and the trial-and-error iterative adjustment (IA) algorithms [16]. A memetic algorithm (MA) was found to be superior to a SPSA algorithm because the fine-tuning process required was significantly quicker for MA [3]. Cobos et al. [20] found that when a MA was adapted, using Solis and Wets local search chains (MA-SWChains), the results provided better and faster convergence compared to both SPSA and MA. A multiobjective MA based on NSGA-II and simulated annealing (NSGA-II-SA) also offered better results for runtime and convergence compared to a single-objective MA [21]. Considering that the performance of the calibration process and the time invested in finding the correct set of hyperparameters are correlated and affected by the characteristics of each metaheuristic, 17 alternative algorithms including multi- and mono-objective approaches were evaluated [22]. An adaptation of the global-best harmony search provided the best results considering both stability and dominance.

Microscopic traffic flow simulation models use the concept of car-following and lane-changing theories to represent vehicle interactions and driver-behavior dynamics $[2,23]$. Typically, calibration parameters are related to driver characteristics, such as car-following behavior and gap acceptance. Balakrishna et al. [16] proposed the calibration of demand-and-supply parameters simultaneously. However, the calibration was performed only with link counts and used precalibrated values for the driver-behavior parameters. Cheu et al. [8] used parameters such as free-flow speeds, car-following distance, car-following sensitivity factors, lagto-accelerate/decelerate factors, and lane-changing factors. Results showed that free-flow speeds, car-following distance, and car-following sensitivity factors had the most effect and are important for calibration; thus, calibration could be performed using only these three parameters. Ma and Kim $[4,13]$ considered calibration parameters that were associated with acceleration/deceleration, car-following, and lane-changing behaviors. The lane-change probability and car-following distance were found to have relatively close calibrated and default values, suggesting that calibration could be performed without the inclusion of these parameters. Performance measures after calibration showed consistency with actual field values; however, no standard criteria for calibration were defined. Paz et al. [3, 6] calibrated microscopic traffic flow models by taking into consideration the entire set of model parameters simultaneously. The simultaneous selection of all parameters was motivated by the need to seek convergence and stability of the solutions. All parameters were treated equally, and a subset of parameters that may significantly affect a traffic model was not identified. Kim [13] used a bilevel framework to calibrate driver-behavior parameters and O-D demand simultaneously. The calibration was performed only on a congested network.

State-of-the-art methods take into consideration sets of links and parameters for calibration without providing flexibility for selecting or constraining the search space in terms of where and what to use to fine-tune the traffic flow simulation model. In practice, only a subset of links and parameters can be used for calibration; for example, certain links of a network may be precalibrated, and/or default or prespecified values are required by local governance. That is, development and calibration may be restricted to adjust only a subset of all the potentially available parameters in a traffic flow model. Based on local knowledge and experience, key parameters and specific traffic facilities are selected or allowed for calibration $[13,24]$. While a large number of parameters increase computational complexity, identifying a subset of important parameters mitigates this problem and increases the ability of an algorithm to find a global optimum [25]. When all the parameters are calibrated simultaneously, lesser-known parameters may yield values that are unexplainable or inconsistent with real-world traffic behavior.

Unlike traditional approaches that either involve a sequential process or consider all parameters simultaneously, this research proposes a methodology that enables the simultaneous selection of specific links/facilities and parameters for calibration. That is, any combination of traffic facilities and model parameters within each facility can be selected simultaneously for calibration. Local and global calibration parameters were taken into consideration. The capability of selecting where and what to calibrate was motivated by requirements to use local knowledge and governance in order to select parameters for calibration. This is of practical and theoretical importance, and these analyses and associated insights are missing in the literature. Our experiments illustrate the consequences of selecting only a subset rather than all parameters.

\section{Methods}

The calibration methodology used in this study was adapted from Paz et al. [3]. This modified approach has the capability to select links and model parameters. The calibration problem was formulated using a mathematical 
programming approach. The normalized root mean square, which was the objective function for this study, measured the relative difference between actual and simulated traffic volumes and speeds. Normalization allowed multiple performance measures to be considered simultaneously [3].

\subsection{Problem Formulation}

2.1.1. Notation and Terms. In this study, any number and combination of local and global parameters could be selected for calibration. Indicator variables $\delta_{k}^{p}$ and $\delta^{g}$ were used to define which parameters were selected. The following are the notations and terms used in this study:

$K$ : set of links selected for calibration

$k$ : subscript for a link selected for calibration, $k \in K$

$P$ : set of local model parameters

$p$ : superscript for a local model parameter, $p \in P$

$\alpha_{k}^{p}$ : local parameter $p$ on link $k$ selected for calibration, $\forall k \in K$ and $p \in P$

$\alpha_{k}$ : set of local parameters on link $k$ selected for calibration, $\forall k \in K$

$\delta_{k}^{p}$ : indicator variable for local parameter $p$ on link $k$ selected for calibration, $\forall k \in K, \quad p \in P$, and $\delta_{k}^{p}=1 \Leftrightarrow \alpha_{k}^{p} \in \alpha_{k}$; otherwise, $\delta_{k}^{p}=0$

$\alpha$ : set of local parameters selected for calibration, $\alpha \in P$

$G$ : set of global model parameters

$g$ : superscript for a global model parameter, $g \in G$

$\beta^{g}$ : global parameter selected for calibration $g, \forall g \in G$

$\beta$ : set of global parameters selected for calibration, $\beta \in G$

$\delta^{g}$ : indicator variable for global parameter $g$ selected for calibration, $\forall g \in G$ and $\delta^{g}=1 \Leftrightarrow \beta^{g} \in \beta$; otherwise, $\delta^{g}=0$

$\theta$ : set of all parameters selected for calibration, $\theta=\alpha \cup \beta$

$L$ : set of links with actual field data

l: subscript for a link with actual field data, $l \in L$

$T$ : total number of time periods

$t$ : subscript for a time period, $t \in T$

$V_{l, t}:$ actual volume for link $l$ at time period $t, \forall t \in T$ and $l \in L$

$S_{l, t}$ : actual speed for link $l$ at time period $t, \forall t \in T$ and $l \in L$

$W_{v}$ : weight factor for volumes

$\widehat{V}(\theta)_{l, t}$ : simulated volume for link $l$ at time period $t$, $\forall t \in T$ and $l \in L$

$\widehat{S}(\theta)_{l, t}:$ simulated speed for link $l$ at time period $t, \forall t \in T$ and $l \in L$

2.1.2. Mathematical Program. The objective function and the calibration criteria were evaluated using links $L$ with the actual field data that were available.
(1) Objective Function. The objective was to minimize the normalized weighted root-mean-square (NRMS) error over the number of time periods $(T)$ and links $(L)$ as follows:

$$
\begin{aligned}
\text { minimize NRMS }= & \frac{1}{\sqrt{|L|}+\sqrt{T \mid}} \\
& * \sum_{t=1}^{T} \sum_{l=1}^{L}\left(W_{v} * \sqrt{\sum_{l}^{|L|}\left(\frac{V_{l, t}-\widehat{V}(\theta)_{l, t}}{V_{l, t}}\right)^{2}}\right. \\
& +\left(1-W_{v}\right) * \sqrt{\left.\sum_{l}^{|L|}\left(\frac{S_{l, t}-\widehat{S}(\theta)_{l, t}}{S_{l, t}}\right)^{2}\right)},
\end{aligned}
$$

subject to

$$
\begin{aligned}
\alpha_{k} & =\left\{\alpha_{k}^{p} \mid \forall \delta_{k}^{p}=1, \forall k \in K, p \in P\right\}, \\
\alpha & =U_{k \in K} \alpha_{k}, \\
\beta & =\left\{\beta^{g} \mid \forall \delta^{g}=1, \forall g \in G\right\}, \\
\theta & =\alpha \cup \beta,
\end{aligned}
$$

lower bound $\leq \alpha_{k}^{p} \leq$ upper bound, $\quad \forall k \in K, p \in P$,

lower bound $\leq \beta^{g} \leq$ upper bound, $\quad \forall g \in G$.

This NRMS error function measures the relative difference between the estimated and the actual volume and speed values. The values in the squared root are the relative differences in volume and speeds for all links selected for calibration that contained actual field data. The relative differences are multiplied by $W_{v}$ and $1-W_{v}$ to consider the reliability of volume and speed data. This difference is also measured for all considered time periods. The total error is normalized by dividing it by the squared root of the number of links and time periods considered for calibration. The NRMS is based on a previous study [3], where this error function was used successfully to calibrate traffic flow models.

Constraints (2) and (3) ensured that the local parameters selected for calibration were included in vector $\theta$. Similarly, constraint (4) ensured that the global parameters selected for calibration were included in vector $\theta$. Constraint (5) was a definitional constraint for the calibration vector $\theta$. Constraints (6) and (7) provided the lower and upper bounds for each parameter selected for calibration.

2.2. Calibration Criteria. The criterion for calibration is based on guidelines provided by the FHWA [2]. For individual links, in more than $85 \%$ of cases, the difference between actual and simulated counts should be

(i) Within 100 vehicles/hour for link volumes less than 700 vehicles/hour 
(ii) Within $15 \%$ of field flow for link volumes between 700 and 2700 vehicles/hour

(iii) Within 400 vehicles/hour for link volumes greater than 2700 vehicles/hour

The sum of all simulated link count errors should be within 5\% of all actual link counts. The GEH statistic for individual link flows should be less than 5 for more than $85 \%$ of cases $[1,2]$. The GEH statistic is given by

$$
\mathrm{GEH}=\sqrt{\frac{2\left(V_{l}-\widehat{V}(\theta)_{l}\right)^{2}}{V_{l}+\widehat{V}(\theta)_{l}}}
$$

where $V_{l}$ is the actual traffic volume for link $l$ and $\widehat{V}(\theta)_{l}$ is the corresponding simulated traffic volume.

2.3. Solution Algorithm. The proposed mathematical program, as expressed in equations (1) through (7), was solved using a GA, which searches solutions by trying to avoid stopping at local optima and seeking to increase the probability of locating a global optimum [4, 5, 8-14, 26, 27]. In the context of the GA, a population is generated at random, initially. An individual (chromosome) in a population is composed by a set of calibration parameter values (genes) that represent a viable solution. Table 1 provides an example of an individual or chromosome used in this study. The parameters to be calibrated are organized into an array where specific positions are associated with certain links. The quality of the resulting solution is evaluated by a fitness or objective function, as in equation (1). GA creates successive generations of individuals, and the best individuals are stored to create a new population. The implemented GA expands the one proposed by $\mathrm{Paz}$ et al. [3] to address constraints (2)-(7) to enable section of links and calibration parameters. Figure 1 provides a flowchart of the GA solution algorithm.

Algorithmic steps are as follows:

Step 1-initialization: an initial population of $\theta_{\mathrm{s}}$ is randomly generated but constrained to lower and upper bounds in order to maintain model realism.

Step 2-parents' selection: the best $60 \%$ of $\theta_{\text {s }}$ from the initial population are saved. Then, sets of $\theta$ are generated that represent parents in the population and are paired using a 'roulette wheel selection.'

Step 3-crossover: a crossover is performed at 50\%. This process combines parent $\theta_{\mathrm{s}}$ in order to generate new sets of calibration parameters (i.e., offspring).

Step 4-mutation: approximately $30 \%$ of the parameters of each offspring are subjected to small perturbations $( \pm 1 \%)$ in order to research neighboring solutions.

Step 5-population management strategy: the new offspring $\theta$ replaces the worst $\theta_{\mathrm{s}}$ when new $\theta$ provides a better fitness than older $\theta_{s}$.

Step 6-stopping criteria: if the stopping criterion is met, best $\theta$ is returned, and the algorithm ends.
Otherwise, it returns to Step 2. The stopping criterion is met by reaching convergence or a prespecified maximum number of generations/iterations. Convergence is researched when the calibration criteria listed above are met.

\section{Experiments and Results}

The proposed methodology and solution algorithm were tested using CORSIM models. CORSIM includes driverbehavior and vehicle performance parameters. Table 2 lists various calibration parameters in CORSIM [3]. Two CORSIM models are used in the experiments and are illustrated in Figure 2. Both models included arterial roads with signalized intersections. For signal-controlled intersections, one of the important parameters was the discharge headway of individual vehicles $[2,28]$. The Reno network (Figure 2(a)) represents the Pyramid Highway in Reno, Nevada, and consists of 126 arterial links. Calibration field data were available for 45 of these links.

The local parameters included the mean queue discharge headway and the mean value of start-up lost time. The global parameters included lane change, acceptable gap in nearside cross-traffic for vehicles at a sign, additional time for farside cross-traffic in the acceptable gap for vehicles at a sign, and the driver's familiarity with path distributions. The McTrans model (Figure 2(b)), provided by McTransTM, consisted of 20 arterial links. This is a well-known model of a synthetic network used only for demonstration and analysis purposes. The default parameters in the McTrans model were considered as calibrated conditions, and the outputs from this model were used as field data for the experiments. Model parameters were randomly modified to represent an uncalibrated model. The local parameters included mean queue discharge headway and mean start-up lost time. Global parameters included the driver's familiarity with path distributions and included the percentage of drivers who knew only one turn movement as well as the percentage of drivers who knew two turn movements.

3.1. Experimental Setup. The proposed solution algorithm was implemented using Java ${ }^{\mathrm{TM}}$, which is capable of handling complex data structures and mathematical functions. As noted by $\mathrm{Paz}$ et al. [3], the implementation used a basic layered architecture, with each layer handling a group of related functions. Volume and speed data were used for the calibration. The CORSIM models were run for a simulation time period of $15 \mathrm{~min}$. The first set of experiments incorporated a selection of links in the network, and the second set of experiments incorporated the simultaneous selection of links and parameters.

3.2. First Set of Experiments: Selection of Links in the Network. In the first set of experiments, links were selected for calibration randomly. All global and local parameters for the selected links were considered simultaneously for calibration. 
TABle 1: Example of an individual (chromosome) for calibration of traffic flow models.

\begin{tabular}{|c|c|c|c|c|c|c|c|c|c|c|c|c|}
\hline \multirow{2}{*}{$\begin{array}{l}\text { Parameter } \\
\text { Values }\end{array}$} & \multicolumn{3}{|c|}{$\begin{array}{c}\text { Mean queue discharge } \\
\text { headway }(\mathrm{sec})\end{array}$} & \multicolumn{3}{|c|}{$\begin{array}{c}\text { Mean start-up lost time } \\
(\mathrm{sec})\end{array}$} & \multicolumn{3}{|c|}{ Through traffic (vehicles) } & \multicolumn{3}{|c|}{$\begin{array}{l}\text { Left-turning traffic } \\
\text { (vehicles) }\end{array}$} \\
\hline & 2.1 & 2.1 & 2.4 & 3.8 & 4.2 & 3.6 & 636 & 836 & 912 & 837 & 875 & 642 \\
\hline Link & 1 & 2 & 3 & 1 & 2 & 3 & 1 & 2 & 3 & 1 & 2 & 3 \\
\hline
\end{tabular}

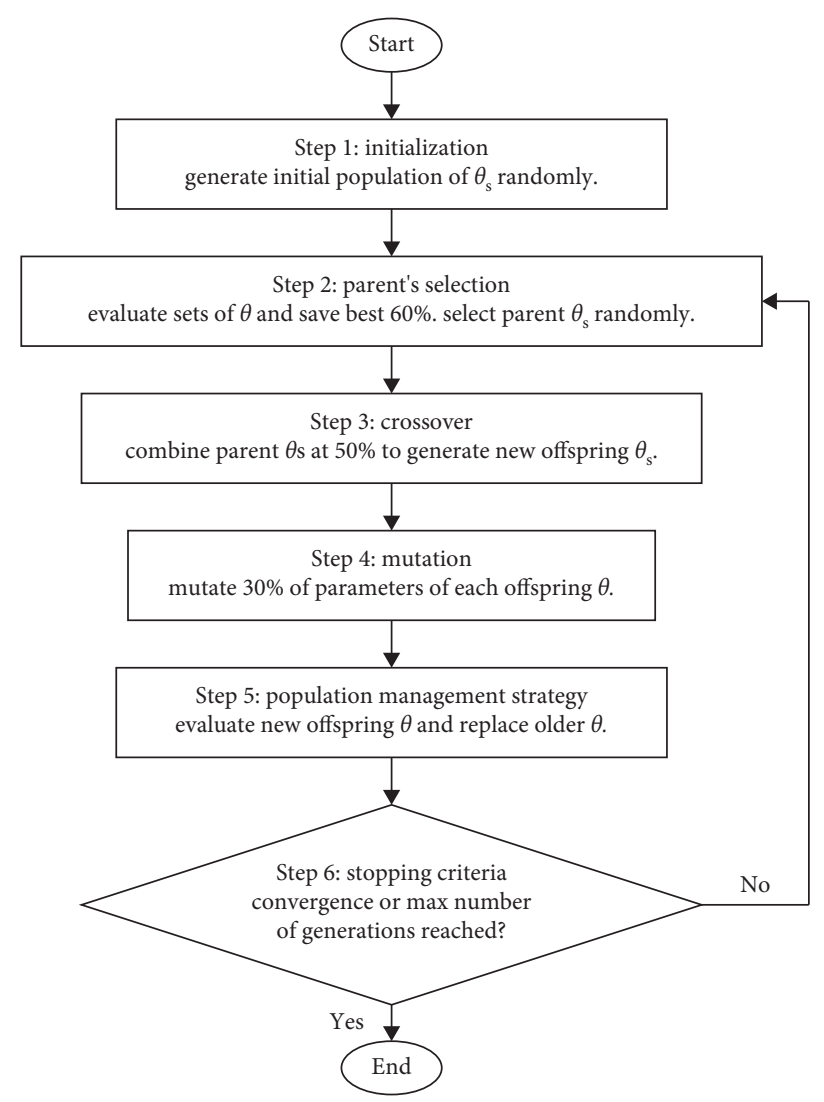

FIgURE 1: Flowchart illustrating the proposed solution algorithm.

When $70 \%$ of links were randomly selected, both models were calibrated successfully. Figure 3 shows how the objective function converged when $70 \%$ of the links were selected for calibration. The normalized root mean square (NRMS) showed improvement over the iterations of the calibration process. For the Reno network, the initial value of NRMS was 0.22; after 845 iterations, the NRMS decreased to 0.08 . For the McTrans model, the initial value of NRMS was 0.29 ; after 370 iterations, the NRMS decreased to 0.06 .

Figure 4 compares vehicle counts before and after calibration. Before calibration, there was a significant difference between the actual and the simulated counts. After calibration, the gap between the actual and simulated counts was reduced, as illustrated by their alignment along the $45^{\circ}$ line in Figure 4.

Figure 5 shows the vehicle speeds before and after calibration. For the Reno network, the speed data are scattered away from the $45^{\circ}$ line more than the volume data. This is a consequence of a higher weight assigned in the objective function to volume than speed. Volume data correspond to vehicle counts, while speed is a spot mean measure which is not representative of the actual speed for the entire link.

Figure 6 shows the GEH statistic for the models before and after calibration. For the Reno network, the initial GEH value was less than 5 for $46 \%$ of the selected links. After calibration, the GEH value was less than 5 for $93 \%$ of the selected links. For the McTrans model, the initial GEH value was less than 5 for $55 \%$ of the selected links. After calibration, the GEH value was less than 5 for $100 \%$ of the links.

Table 3 outlines the percentage of selected links and the corresponding calibration results when all the parameters were selected simultaneously for calibration. Both models were calibrated successfully when at least $60 \%$ of the links were selected. For illustration purposes, Appendix provides the calibration parameters used in the first set of experiments including upper and lower bounds as well as values before and after calibration. All calibrated values are within the accepted range. 
TABLE 2: Calibration parameter in CORSIM models [3].

\begin{tabular}{lcc}
\hline Driver behavior & Vehicle performance & Demand patterns \\
\hline NETSIM model (surface streets) & Speed and acceleration characteristics & $\begin{array}{c}\text { Surface street turn } \\
\text { movements }\end{array}$ \\
Queue discharge headway & Fleet distribution and passenger \\
Start-up lost time & & \\
Distribution of free-flow speed by driver type & \\
Mean duration of parking maneuvers & \\
Lane-change parameters & \\
Maximum left- and right-turning speeds & \\
Probability of joining spillback & \\
Probability of left-turn jumpers and lagers & \\
Gap acceptance at stop signs & \\
Gap acceptance for left and right turns & \\
Pedestrian delays & \\
Driver familiarity with their path & & Freeway turn movements \\
\hline FRESIM model (freeways) & Speed and acceleration characteristics \\
Mean start-up delay at ramp meters & Fleet distribution and passenger \\
Distribution of free-flow speed by driver type & occupancy \\
Incident rubbernecking factor & \\
Car-following sensitivity factor & Maximum deceleration values \\
Lane change gap acceptance parameters & \\
Parameters that affect the number of discretionary lane \\
changes
\end{tabular}

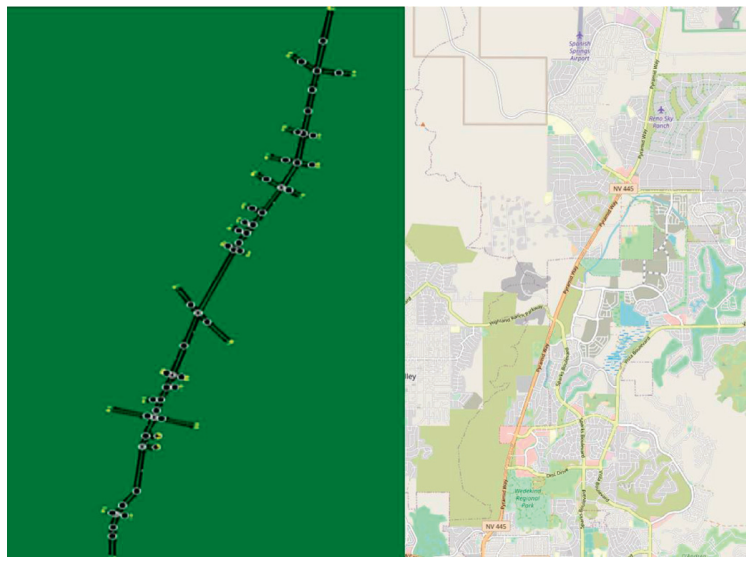

(a)

FIgure 2: CORSIM models used in the experiments: (a) Reno network (Pyramid Highway); (b) McTrans model.

(b)

\subsection{Second Set of Experiments: Simultaneous Selection of Links} and Parameters. In the second set of experiments, links and associated parameters were selected simultaneously. These experiments were conducted using different combinations of parameters.

3.3.1. First Combination. The local parameters were selected for every link, and the global parameters were set as the default. Table 4 shows the selected percentage of links and the corresponding results when only the local parameters were selected for calibration. The Reno network was calibrated successfully when at least $70 \%$ of links were selected for calibration. The McTrans model was successfully calibrated when at least $50 \%$ of links were selected for calibration.

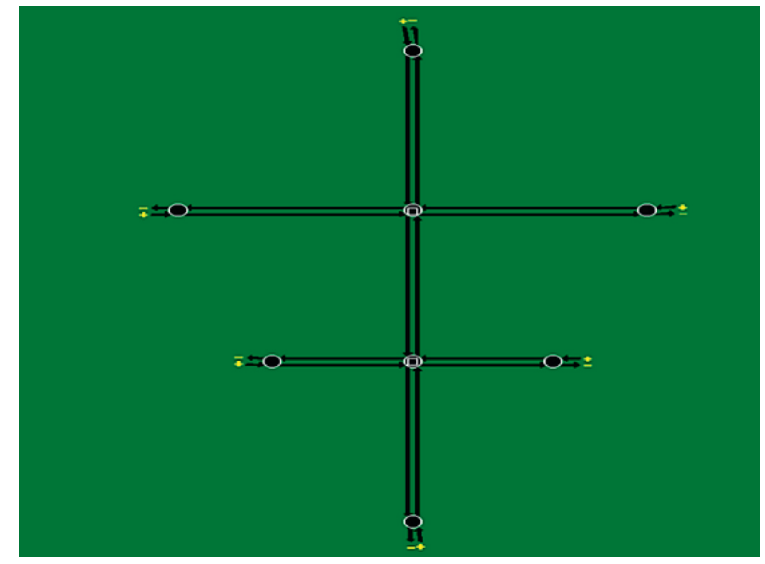

3.3.2. Second Combination. The mean queue discharge headway was selected as the only local parameter for calibration, and all the global parameters were considered. Table 5 provides the results when the mean queue discharge headway and all the global parameters were selected for calibration. Both models were calibrated successfully when at least $60 \%$ of the links were selected for calibration.

3.3.3. Third Combination. Mean queue discharge headway and mean start-up lost time were selected as mutually exclusive; meanwhile, all the global parameters were considered for calibration. Table 6 provides the results from using various percentages of the mean queue discharge headway and mean start-up lost time when all global parameters were considered for calibration of the CORSIM models. The Reno 


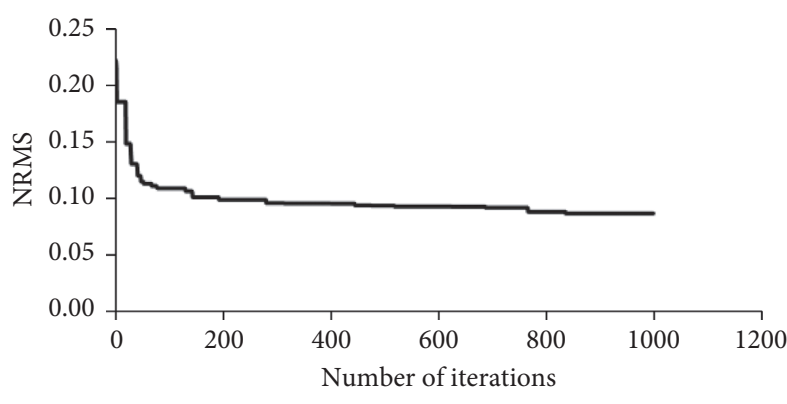

(a)

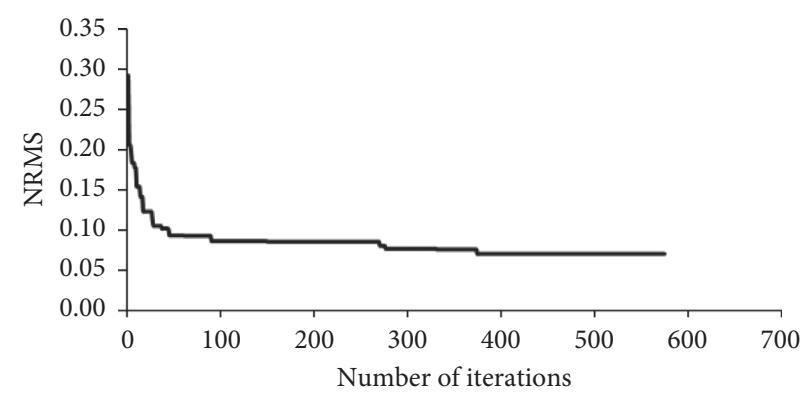

(b)

Figure 3: Objective function for 70\% selection of links for the (a) Reno network and (b) McTrans model.
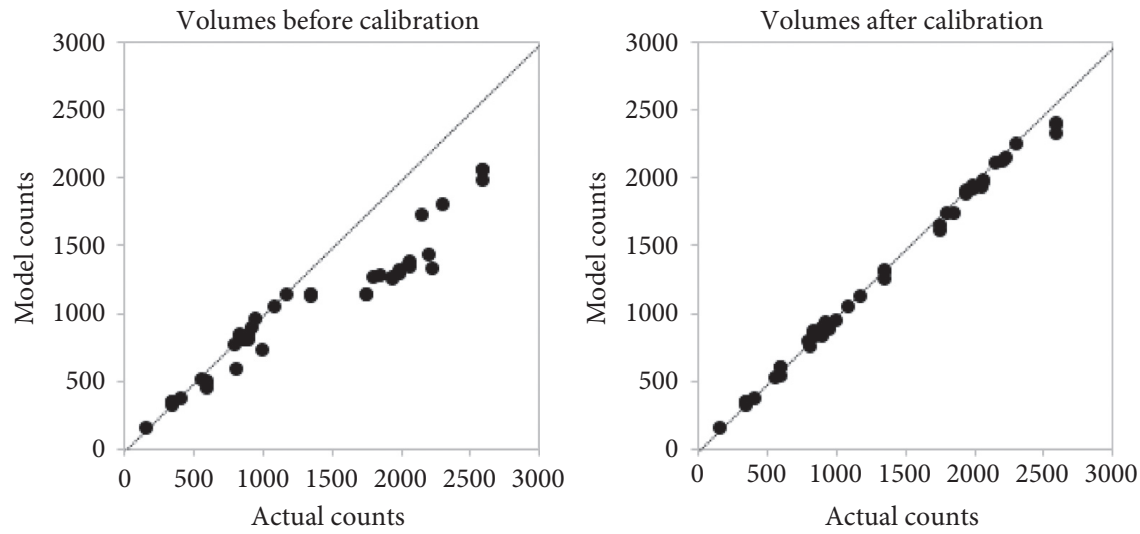

(a)
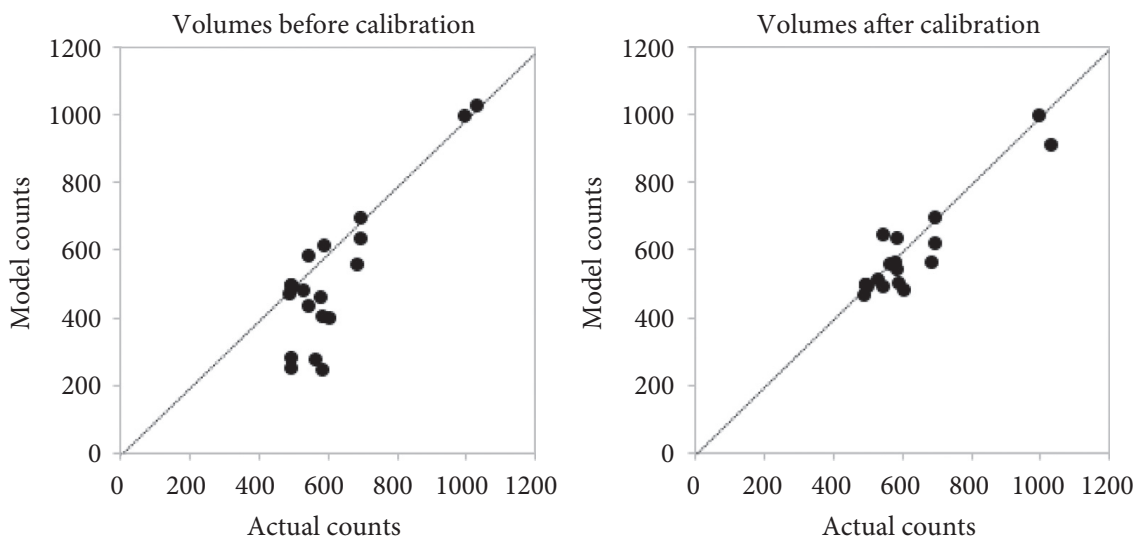

(b)

FIgURE 4: Vehicle counts before and after calibration for the (a) Reno model and (b) McTrans model.

network was calibrated successfully when the mean queue discharge headway was selected for at least $80 \%$ of links; the mean start-up lost time was selected for the remaining $20 \%$ of the links. The McTrans model was calibrated successfully when the mean queue discharge headway was selected for at least $90 \%$ of links, and mean start-up lost time was selected for the remaining $10 \%$ of links.
3.4. Sensitivity Analysis. Sensitivity analyses were conducted to observe the effects on NRMS on various percentage of links and several combinations of parameters selected for calibration. The results are illustrated in Figures 7 and 8 . Figure 7 shows the effects on NRMS due to various percentages of links selected for calibration. In Figure 8, 

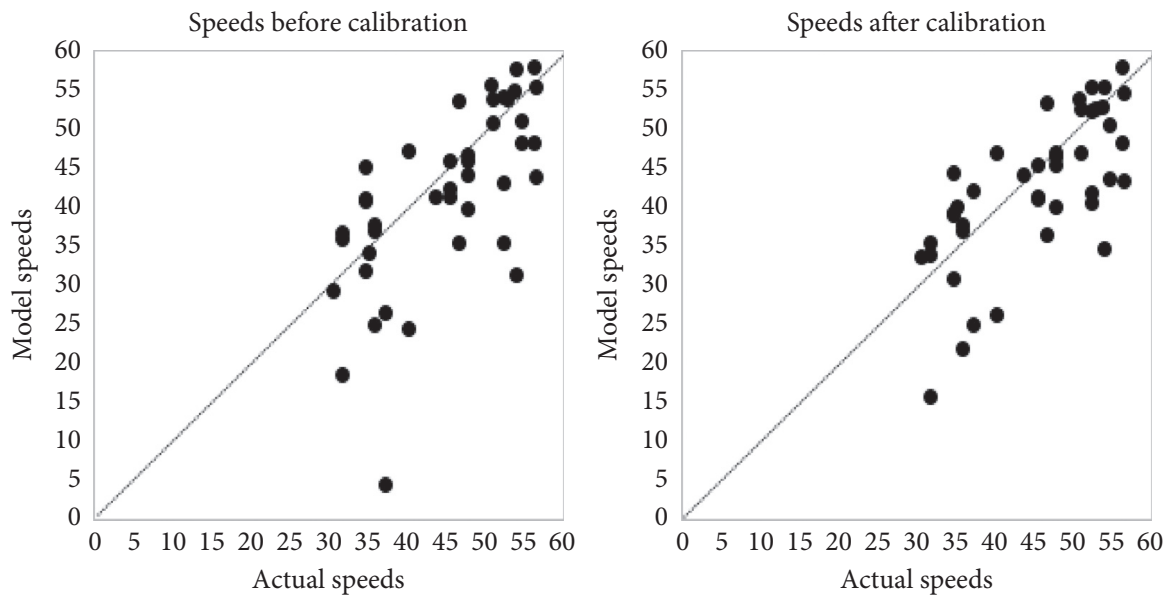

(a)
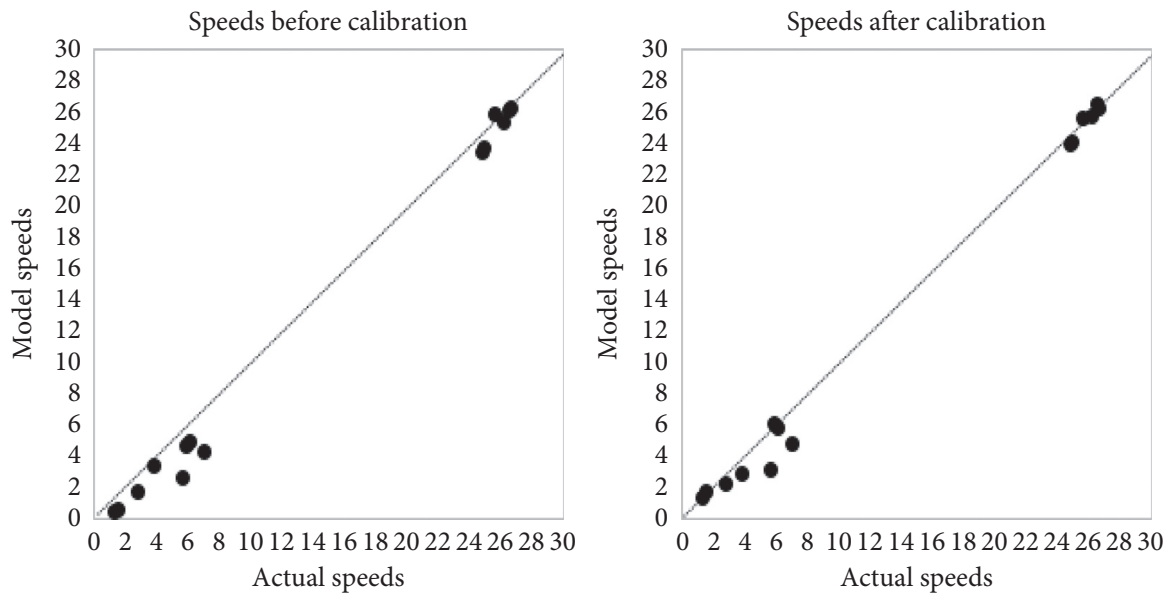

(b)

Figure 5: Speeds before and after calibration for the (a) Reno network and (b) McTrans model.

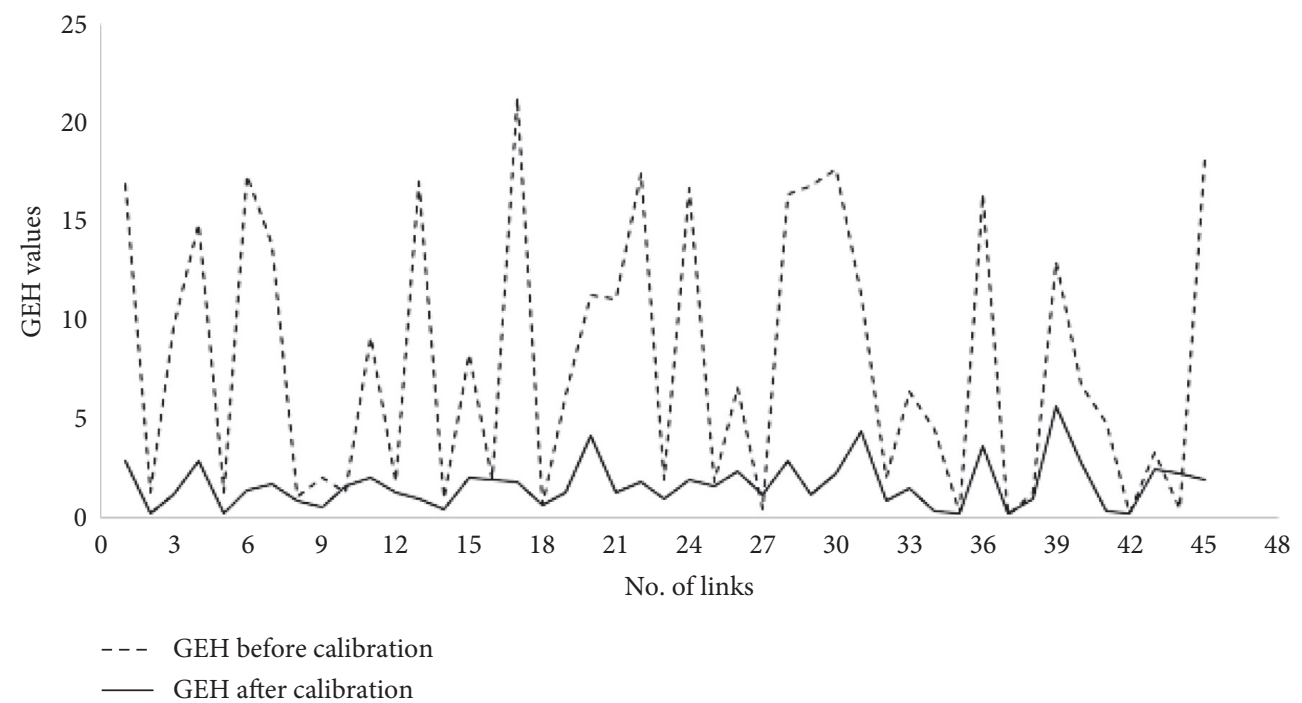

(a)

Figure 6: Continued. 


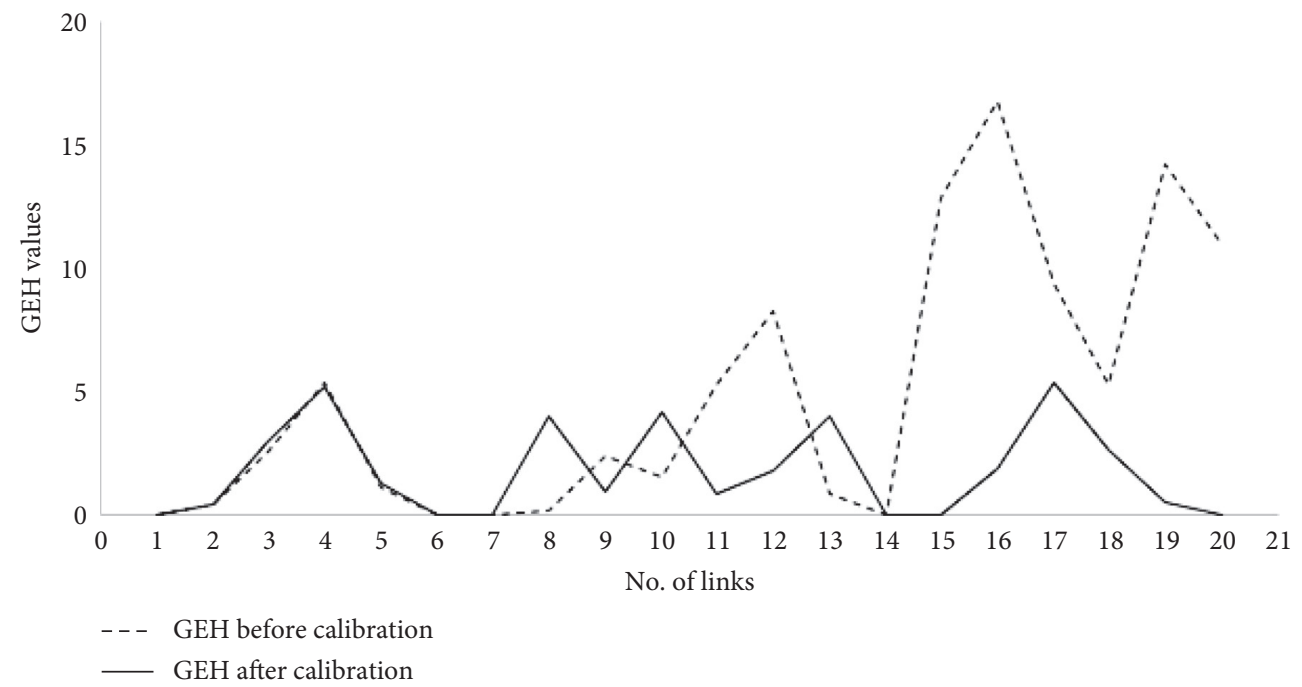

(b)

Figure 6: GEH statistic before and after calibration for the (a) Reno network and (b) McTrans model.

TABLE 3: Calibration results when all parameters were selected simultaneously.

\begin{tabular}{|c|c|c|c|c|c|c|}
\hline \multirow{2}{*}{$\begin{array}{l}\text { Percentage of links } \\
\text { selected for calibration }\end{array}$} & \multirow{2}{*}{ NRMS } & \multicolumn{3}{|c|}{ Individual link flows } & \multirow{2}{*}{$\begin{array}{l}\text { Relative difference between total } \\
\text { actual and simulated counts }\end{array}$} & \multirow{2}{*}{$\begin{array}{l}\text { GEH statistic for } \\
\text { individual link flows }\end{array}$} \\
\hline & & $<700 \mathrm{veh} / \mathrm{hr}$ & 700 to $2700 \mathrm{veh} / \mathrm{hr}$ & $>2700 \mathrm{veh} / \mathrm{hr}$ & & \\
\hline \multicolumn{7}{|l|}{ For the Reno network } \\
\hline 100 & 0.0751 & 100 & 100 & N/A & 1.20 & $<5$ for $100 \%$ \\
\hline 90 & 0.0966 & 100 & 100 & $\mathrm{~N} / \mathrm{A}$ & 4.50 & $<5$ for $97 \%$ \\
\hline 80 & 0.0845 & 100 & 100 & $\mathrm{~N} / \mathrm{A}$ & 3.30 & $<5$ for $100 \%$ \\
\hline 70 & 0.0862 & 100 & 100 & $\mathrm{~N} / \mathrm{A}$ & 4.20 & $<5$ for $93 \%$ \\
\hline 60 & 0.0919 & 100 & 100 & N/A & 4.50 & $<5$ for $100 \%$ \\
\hline 50 & 0.1068 & 88.90 & 100 & $\mathrm{~N} / \mathrm{A}$ & 6.90 & $<5$ for $93 \%$ \\
\hline 40 & 0.1119 & 100 & 100 & $\mathrm{~N} / \mathrm{A}$ & 7.30 & $<5$ for $88 \%$ \\
\hline 30 & 0.1285 & 90 & 88.60 & $\mathrm{~N} / \mathrm{A}$ & 10.20 & $<5$ for $73 \%$ \\
\hline 20 & 0.1555 & 90 & 57.10 & N/A & 13.70 & $<5$ for $57 \%$ \\
\hline \multicolumn{7}{|l|}{ For the McTrans model } \\
\hline 100 & 0.0305 & 100 & 100 & $\mathrm{~N} / \mathrm{A}$ & 0.30 & $<5$ for $100 \%$ \\
\hline 90 & 0.0463 & 100 & 100 & $\mathrm{~N} / \mathrm{A}$ & 0.20 & $<5$ for $100 \%$ \\
\hline 80 & 0.0317 & 100 & 100 & N/A & 0.40 & $<5$ for $100 \%$ \\
\hline 70 & 0.0697 & 100 & 100 & N/A & 0.50 & $<5$ for $100 \%$ \\
\hline 60 & 0.1366 & 89 & 100 & N/A & 2.60 & $<5$ for $95 \%$ \\
\hline 50 & 0.1835 & 72 & 100 & N/A & 5.00 & $<5$ for $85 \%$ \\
\hline 40 & 0.1980 & 78 & 100 & N/A & 9.60 & $<5$ for $80 \%$ \\
\hline
\end{tabular}

TABle 4: Calibration results when only local parameters were selected.

\begin{tabular}{|c|c|c|c|c|c|c|}
\hline \multirow{2}{*}{$\begin{array}{l}\text { Percentage of links } \\
\text { selected for calibration }\end{array}$} & \multirow{2}{*}{ NRMS } & \multicolumn{3}{|c|}{ Individual link flows } & \multirow{2}{*}{$\begin{array}{l}\text { Relative difference between total } \\
\text { actual and simulated counts }\end{array}$} & \multirow{2}{*}{$\begin{array}{l}\text { GEH statistic for } \\
\text { individual link flows }\end{array}$} \\
\hline & & $<700 \mathrm{veh} / \mathrm{hr}$ & 700 to $2700 \mathrm{veh} / \mathrm{hr}$ & $>2700 \mathrm{veh} / \mathrm{hr}$ & & \\
\hline \multicolumn{7}{|l|}{ For the Reno network } \\
\hline 100 & 0.0884 & 100 & 100 & N/A & 4.00 & $<5$ for $100 \%$ \\
\hline 90 & 0.0860 & 100 & 100 & N/A & 3.20 & $<5$ for $100 \%$ \\
\hline 80 & 0.0873 & 100 & 100 & N/A & 3.10 & $<5$ for $100 \%$ \\
\hline 70 & 0.0946 & 100 & 100 & N/A & 3.40 & $<5$ for $95 \%$ \\
\hline 60 & 0.1369 & 100 & 71.4 & N/A & 11 & $<5$ for $64 \%$ \\
\hline \multicolumn{7}{|c|}{ For the McTrans model } \\
\hline 100 & 0.0480 & 100 & 100 & $\mathrm{~N} / \mathrm{A}$ & 0.60 & $<5$ for $100 \%$ \\
\hline
\end{tabular}


TABle 4: Continued.

\begin{tabular}{|c|c|c|c|c|c|c|}
\hline \multirow{2}{*}{$\begin{array}{l}\text { Percentage of links } \\
\text { selected for calibration }\end{array}$} & \multirow{2}{*}{ NRMS } & \multicolumn{3}{|c|}{ Individual link flows } & \multirow{2}{*}{$\begin{array}{l}\text { Relative difference between total } \\
\text { actual and simulated counts }\end{array}$} & \multirow{2}{*}{$\begin{array}{l}\text { GEH statistic for } \\
\text { individual link flows }\end{array}$} \\
\hline & & $<700 \mathrm{veh} / \mathrm{hr}$ & 700 to $2700 \mathrm{veh} / \mathrm{hr}$ & $>2700 \mathrm{veh} / \mathrm{hr}$ & & \\
\hline 90 & 0.0421 & 100 & 100 & N/A & 0.40 & $<5$ for $100 \%$ \\
\hline 80 & 0.1249 & 89 & 100 & N/A & 3.60 & $<5$ for $100 \%$ \\
\hline 70 & 0.0924 & 94.40 & 100 & $\mathrm{~N} / \mathrm{A}$ & 1.40 & $<5$ for $100 \%$ \\
\hline 60 & 0.0974 & 100 & 100 & $\mathrm{~N} / \mathrm{A}$ & 2.70 & $<5$ for $100 \%$ \\
\hline 50 & 0.0959 & 94.40 & 100 & N/A & 3 & $<5$ for $100 \%$ \\
\hline 40 & 0.1367 & 88.20 & 66.70 & N/A & 2.70 & $<5$ for $90 \%$ \\
\hline
\end{tabular}

TABLE 5: Calibration results when all global parameters and mean queue discharge headway were selected.

\begin{tabular}{|c|c|c|c|c|c|c|}
\hline $\begin{array}{l}\text { Percentage of links } \\
\text { selected for calibration }\end{array}$ & NRMS & $<700 \mathrm{veh} / \mathrm{hr}$ & $\begin{array}{l}\text { Individual link flows } \\
700 \text { to } 2700 \mathrm{veh} / \mathrm{hr}\end{array}$ & $>2700 \mathrm{veh} / \mathrm{hr}$ & $\begin{array}{l}\text { Relative difference between total } \\
\text { actual and simulated counts }\end{array}$ & $\begin{array}{l}\text { GEH statistic for } \\
\text { individual link flows }\end{array}$ \\
\hline \multicolumn{7}{|l|}{ For the Reno network } \\
\hline 100 & 0.0872 & 100 & 100 & $\mathrm{~N} / \mathrm{A}$ & 2.7 & $<5$ for $100 \%$ \\
\hline 90 & 0.0970 & 100 & 100 & $\mathrm{~N} / \mathrm{A}$ & 5.2 & $<5$ for $93 \%$ \\
\hline 80 & 0.0976 & 100 & 100 & $\mathrm{~N} / \mathrm{A}$ & 4 & $<5$ for $97 \%$ \\
\hline 70 & 0.0897 & 100 & 100 & $\mathrm{~N} / \mathrm{A}$ & 3.9 & $<5$ for $100 \%$ \\
\hline 60 & 0.0916 & 100 & 100 & $\mathrm{~N} / \mathrm{A}$ & 5 & $<5$ for $100 \%$ \\
\hline 50 & 0.1037 & 100 & 100 & N/A & 5.9 & $<5$ for $93 \%$ \\
\hline \multicolumn{7}{|l|}{ For the McTrans model } \\
\hline 100 & 0.0860 & 94.1 & 100 & $\mathrm{~N} / \mathrm{A}$ & 1.3 & $<5$ for $95 \%$ \\
\hline 90 & 0.0588 & 100 & 100 & $\mathrm{~N} / \mathrm{A}$ & 0.6 & $<5$ for $100 \%$ \\
\hline 80 & 0.0980 & 94.4 & 100 & $\mathrm{~N} / \mathrm{A}$ & 0.9 & $<5$ for $95 \%$ \\
\hline 70 & 0.1279 & 88.9 & 100 & $\mathrm{~N} / \mathrm{A}$ & 2.2 & $<5$ for $95 \%$ \\
\hline 60 & 0.1257 & 94.1 & 100 & $\mathrm{~N} / \mathrm{A}$ & 2.7 & $<5$ for $95 \%$ \\
\hline 50 & 0.1737 & 77.8 & 100 & N/A & 5.5 & $<5$ for $80 \%$ \\
\hline
\end{tabular}

TABLE 6: Calibration results when selection of the mean queue discharge headway and mean start-up lost time was mutually exclusive.

\begin{tabular}{|c|c|c|c|c|c|c|c|}
\hline \multirow{2}{*}{$\begin{array}{l}\text { Percentage of links } \\
\text { selected with mean } \\
\text { queue discharge } \\
\text { headway }\end{array}$} & \multirow{2}{*}{$\begin{array}{l}\text { Percentage of links } \\
\text { selected with mean } \\
\text { start-up lost time }\end{array}$} & \multirow[b]{2}{*}{ NRMS } & \multicolumn{3}{|c|}{ Individual link flows } & \multirow{2}{*}{$\begin{array}{c}\text { Relative difference } \\
\text { between total actual } \\
\text { and simulated counts } \\
(\%)\end{array}$} & \multirow{2}{*}{$\begin{array}{l}\text { GEH statistic for } \\
\text { individual link } \\
\text { flows }\end{array}$} \\
\hline & & & $\begin{array}{c}<700 \text { veh/ } \\
\text { hr }(\%)\end{array}$ & $\begin{array}{c}700 \text { to } \\
2700 \mathrm{veh} / \mathrm{hr} \\
(\%)\end{array}$ & $\begin{array}{c}>2700 \text { veh/ } \\
\mathrm{hr}\end{array}$ & & \\
\hline \multicolumn{8}{|l|}{ For the Reno network } \\
\hline 90 & 10 & 0.0909 & 100 & 100 & N/A & 4.2 & $<5$ for $97 \%$ \\
\hline 80 & 20 & 0.0930 & 100 & 100 & N/A & 4.7 & $<5$ for $100 \%$ \\
\hline 70 & 30 & 0.0947 & 100 & 100 & N/A & 5.4 & $<5$ for $97 \%$ \\
\hline \multicolumn{8}{|c|}{ For the McTrans network } \\
\hline 90 & 10 & 0.0679 & 94.1 & 100.00 & N/A & 0.7 & $<5$ for $100 \%$ \\
\hline 80 & 20 & 0.1827 & 72.2 & 100.00 & N/A & 8.2 & $<5$ for $80 \%$ \\
\hline 70 & 30 & 0.1746 & 82.4 & 66.7 & N/A & 6.2 & $<5$ for $80 \%$ \\
\hline
\end{tabular}

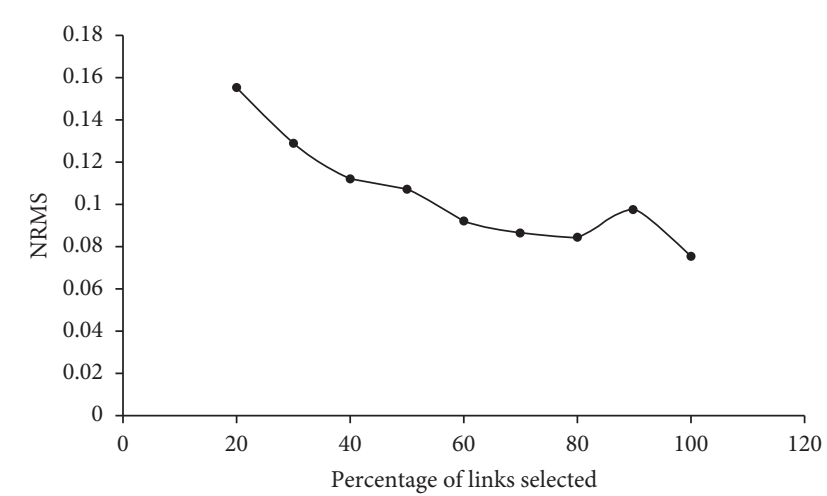

(a)

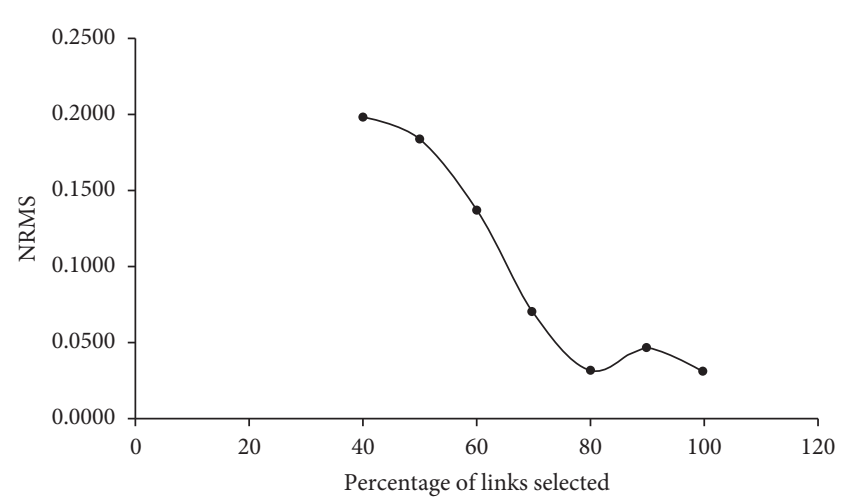

(b)

FIgURE 7: Effect on NRMS of various percentages of link selection for calibration. (a) Reno network. (b) McTrans network. 


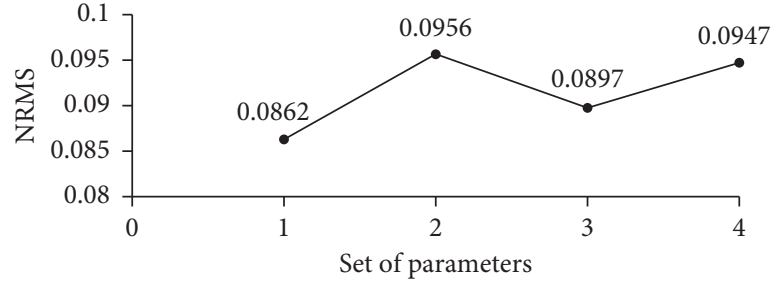

(a)

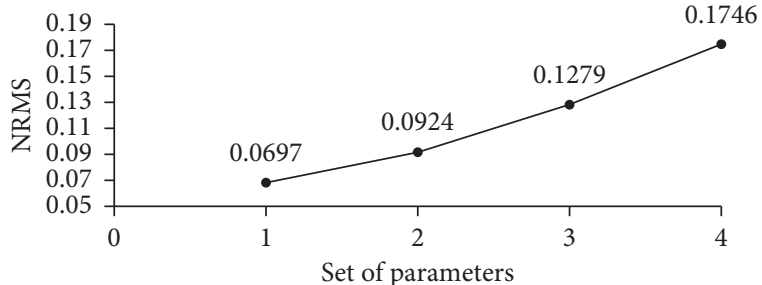

(b)

Figure 8: Effect on NRMS of various sets of parameters for calibration. (a) Reno network. (b) McTrans network.

TABLE 7: Calibration parameters in the first experiment using the Reno network.

\begin{tabular}{|c|c|c|c|c|c|c|c|c|}
\hline $\mathrm{SN}$ & Model & Parameter & $\begin{array}{l}\text { Lower } \\
\text { bound }\end{array}$ & $\begin{array}{l}\text { Upper } \\
\text { bound }\end{array}$ & Units & Links & $\begin{array}{c}\text { Value } \\
\text { before } \\
\text { calibration }\end{array}$ & $\begin{array}{l}\text { Value after } \\
\text { calibration }\end{array}$ \\
\hline 1 & NETSIM & Mean queue discharge headway & 14 & 99 & Tenths of seconds & $1-26$ & 38 & 41 \\
\hline 2 & NETSIM & Mean queue discharge headway & 14 & 99 & Tenths of seconds & $1-41$ & 36 & 42 \\
\hline 3 & NETSIM & Mean queue discharge headway & 14 & 99 & Tenths of seconds & $2-38$ & 40 & 42 \\
\hline 4 & NETSIM & Mean queue discharge headway & 14 & 99 & Tenths of seconds & $3-27$ & 38 & 38 \\
\hline 5 & NETSIM & Mean queue discharge headway & 14 & 99 & Tenths of seconds & $4-33$ & 36 & 48 \\
\hline 6 & NETSIM & Mean queue discharge headway & 14 & 99 & Tenths of seconds & $4-35$ & 38 & 85 \\
\hline 7 & NETSIM & Mean queue discharge headway & 14 & 99 & Tenths of seconds & $5-42$ & 38 & 30 \\
\hline 8 & NETSIM & Mean queue discharge headway & 14 & 99 & Tenths of seconds & $6-48$ & 38 & 75 \\
\hline 9 & NETSIM & Mean queue discharge headway & 14 & 99 & Tenths of seconds & $7-19$ & 38 & 48 \\
\hline 10 & NETSIM & Mean queue discharge headway & 14 & 99 & Tenths of seconds & $8-21$ & 40 & 81 \\
\hline 11 & NETSIM & Mean queue discharge headway & 14 & 99 & Tenths of seconds & $9-25$ & 36 & 38 \\
\hline 12 & NETSIM & Mean queue discharge headway & 14 & 99 & Tenths of seconds & $10-31$ & 40 & 56 \\
\hline 13 & NETSIM & Mean queue discharge headway & 14 & 99 & Tenths of seconds & $13-39$ & 36 & 89 \\
\hline 14 & NETSIM & Mean queue discharge headway & 14 & 99 & Tenths of seconds & $13-40$ & 38 & 34 \\
\hline 15 & NETSIM & Mean queue discharge headway & 14 & 99 & Tenths of seconds & $14-43$ & 36 & 40 \\
\hline 16 & NETSIM & Mean queue discharge headway & 14 & 99 & Tenths of seconds & $14-44$ & 40 & 42 \\
\hline 17 & NETSIM & Mean queue discharge headway & 14 & 99 & Tenths of seconds & $15-47$ & 40 & 48 \\
\hline 18 & NETSIM & Mean queue discharge headway & 14 & 99 & Tenths of seconds & $16-49$ & 26 & 48 \\
\hline 19 & NETSIM & Mean queue discharge headway & 14 & 99 & Tenths of seconds & $16-51$ & 28 & 61 \\
\hline 20 & NETSIM & Mean queue discharge headway & 14 & 99 & Tenths of seconds & $22-45$ & 28 & 26 \\
\hline 21 & NETSIM & Mean queue discharge headway & 14 & 99 & Tenths of seconds & $11-10$ & 28 & 48 \\
\hline 22 & NETSIM & Mean queue discharge headway & 14 & 99 & Tenths of seconds & $2-3$ & 26 & 36 \\
\hline 23 & NETSIM & Mean queue discharge headway & 14 & 99 & Tenths of seconds & $11-12$ & 30 & 44 \\
\hline 24 & NETSIM & Mean queue discharge headway & 14 & 99 & Tenths of seconds & $12-11$ & 30 & 32 \\
\hline 25 & NETSIM & Mean queue discharge headway & 14 & 99 & Tenths of seconds & $5-6$ & 26 & 50 \\
\hline 26 & NETSIM & Mean queue discharge headway & 14 & 99 & Tenths of seconds & $12-13$ & 23 & 21 \\
\hline 27 & NETSIM & Mean queue discharge headway & 14 & 99 & Tenths of seconds & $13-12$ & 30 & 22 \\
\hline 28 & NETSIM & Mean queue discharge headway & 14 & 99 & Tenths of seconds & $6-5$ & 30 & 30 \\
\hline 29 & NETSIM & Mean queue discharge headway & 14 & 99 & Tenths of seconds & $13-14$ & 30 & 38 \\
\hline 30 & NETSIM & Mean queue discharge headway & 14 & 99 & Tenths of seconds & $14-15$ & 48 & 90 \\
\hline 31 & NETSIM & Mean queue discharge headway & 14 & 99 & Tenths of seconds & $15-14$ & 48 & 18 \\
\hline 32 & NETSIM & Mean queue discharge headway & 14 & 99 & Tenths of seconds & $3-4$ & 45 & 15 \\
\hline 33 & NETSIM & Mean queue discharge headway & 14 & 99 & Tenths of seconds & $51-16$ & 38 & 28 \\
\hline 34 & NETSIM & Mean queue discharge headway & 14 & 99 & Tenths of seconds & $17-1$ & 34 & 38 \\
\hline 35 & NETSIM & Mean queue discharge headway & 14 & 99 & Tenths of seconds & $20-2$ & 34 & 38 \\
\hline 36 & NETSIM & Mean queue discharge headway & 14 & 99 & Tenths of seconds & $43-14$ & 30 & 34 \\
\hline 37 & NETSIM & Mean queue discharge headway & 14 & 99 & Tenths of seconds & $21-8$ & 38 & 28 \\
\hline 38 & NETSIM & Mean queue discharge headway & 14 & 99 & Tenths of seconds & $22-1$ & 34 & 24 \\
\hline 39 & NETSIM & Mean queue discharge headway & 14 & 99 & Tenths of seconds & $23-8$ & 34 & 19 \\
\hline 40 & NETSIM & Mean queue discharge headway & 14 & 99 & Tenths of seconds & $44-14$ & 38 & 90 \\
\hline 41 & NETSIM & Mean queue discharge headway & 14 & 99 & Tenths of seconds & $24-9$ & 30 & 34 \\
\hline 42 & NETSIM & Mean queue discharge headway & 14 & 99 & Tenths of seconds & $52-5$ & 38 & 38 \\
\hline 43 & NETSIM & Mean queue discharge headway & 14 & 99 & Tenths of seconds & $26-1$ & 30 & 57 \\
\hline 44 & NETSIM & Mean queue discharge headway & 14 & 99 & Tenths of seconds & $30-9$ & 30 & 67 \\
\hline 45 & NETSIM & Mean queue discharge headway & 14 & 99 & Tenths of seconds & $30-10$ & 28 & 70 \\
\hline
\end{tabular}


TABle 7: Continued.

\begin{tabular}{|c|c|c|c|c|c|c|c|c|}
\hline $\mathrm{SN}$ & Model & Parameter & $\begin{array}{l}\text { Lower } \\
\text { bound }\end{array}$ & $\begin{array}{l}\text { Upper } \\
\text { bound }\end{array}$ & Units & Links & $\begin{array}{c}\text { Value } \\
\text { before } \\
\text { calibration }\end{array}$ & $\begin{array}{l}\text { Value after } \\
\text { calibration }\end{array}$ \\
\hline 46 & NETSIM & Mean queue discharge headway & 14 & 99 & Tenths of seconds & $33-4$ & 26 & 20 \\
\hline 47 & NETSIM & Mean queue discharge headway & 14 & 99 & Tenths of seconds & $28-15$ & 30 & 74 \\
\hline 48 & NETSIM & Mean queue discharge headway & 14 & 99 & Tenths of seconds & $35-4$ & 30 & 26 \\
\hline 49 & NETSIM & Mean queue discharge headway & 14 & 99 & Tenths of seconds & $54-16$ & 28 & 30 \\
\hline 50 & NETSIM & Mean queue discharge headway & 14 & 99 & Tenths of seconds & $49-16$ & 28 & 32 \\
\hline 51 & NETSIM & Mean queue discharge headway & 14 & 99 & Tenths of seconds & $55-7$ & 26 & 26 \\
\hline 52 & NETSIM & Mean queue discharge headway & 14 & 99 & Tenths of seconds & $40-13$ & 20 & 14 \\
\hline 53 & NETSIM & Mean queue discharge headway & 14 & 99 & Tenths of seconds & $41-1$ & 28 & 14 \\
\hline 54 & NETSIM & Mean queue discharge headway & 14 & 99 & Tenths of seconds & $55-8$ & 30 & 22 \\
\hline 55 & NETSIM & Mean queue discharge headway & 14 & 99 & Tenths of seconds & $27-3$ & 36 & 38 \\
\hline 56 & NETSIM & Mean queue discharge headway & 14 & 99 & Tenths of seconds & $4-52$ & 36 & 38 \\
\hline 57 & NETSIM & Mean queue discharge headway & 14 & 99 & Tenths of seconds & $31-10$ & 38 & 74 \\
\hline 58 & NETSIM & Mean queue discharge headway & 14 & 99 & Tenths of seconds & $17-20$ & 38 & 32 \\
\hline 59 & NETSIM & Mean queue discharge headway & 14 & 99 & Tenths of seconds & $2-20$ & 36 & 96 \\
\hline 60 & NETSIM & Mean queue discharge headway & 14 & 99 & Tenths of seconds & $34-11$ & 38 & 89 \\
\hline 61 & NETSIM & Mean queue discharge headway & 14 & 99 & Tenths of seconds & $28-54$ & 40 & 87 \\
\hline 62 & NETSIM & Mean queue discharge headway & 14 & 99 & Tenths of seconds & $16-54$ & 36 & 22 \\
\hline 63 & NETSIM & Mean queue discharge headway & 14 & 99 & Tenths of seconds & $7-55$ & 40 & 48 \\
\hline 64 & NETSIM & Mean queue discharge headway & 14 & 99 & Tenths of seconds & $38-2$ & 36 & 24 \\
\hline 65 & NETSIM & Mean queue discharge headway & 14 & 99 & Tenths of seconds & $8-55$ & 36 & 59 \\
\hline 66 & NETSIM & Mean queue discharge headway & 14 & 99 & Tenths of seconds & $25-9$ & 50 & 50 \\
\hline 67 & NETSIM & Mean queue discharge headway & 14 & 99 & Tenths of seconds & 8018-18 & 40 & 42 \\
\hline 68 & NETSIM & Mean queue discharge headway & 14 & 99 & Tenths of seconds & $8021-21$ & 50 & 46 \\
\hline 69 & NETSIM & Mean queue discharge headway & 14 & 99 & Tenths of seconds & $8023-23$ & 44 & 40 \\
\hline 70 & NETSIM & Mean queue discharge headway & 14 & 99 & Tenths of seconds & $8024-24$ & 48 & 50 \\
\hline 71 & NETSIM & Mean queue discharge headway & 14 & 99 & Tenths of seconds & $8027-27$ & 46 & 36 \\
\hline 72 & NETSIM & Mean queue discharge headway & 14 & 99 & Tenths of seconds & $8031-31$ & 48 & 45 \\
\hline 73 & NETSIM & Mean queue discharge headway & 14 & 99 & Tenths of seconds & $8033-33$ & 44 & 50 \\
\hline 74 & NETSIM & Mean queue discharge headway & 14 & 99 & Tenths of seconds & $8035-35$ & 50 & 87 \\
\hline 75 & NETSIM & Mean queue discharge headway & 14 & 99 & Tenths of seconds & $8038-38$ & 48 & 23 \\
\hline 76 & NETSIM & Mean queue discharge headway & 14 & 99 & Tenths of seconds & 8039-39 & 49 & 51 \\
\hline 77 & NETSIM & Mean queue discharge headway & 14 & 99 & Tenths of seconds & $8040-40$ & 40 & 92 \\
\hline 78 & NETSIM & Mean queue discharge headway & 14 & 99 & Tenths of seconds & $8041-41$ & 50 & 21 \\
\hline 79 & NETSIM & Mean queue discharge headway & 14 & 99 & Tenths of seconds & $8043-43$ & 48 & 46 \\
\hline 80 & NETSIM & Mean queue discharge headway & 14 & 99 & Tenths of seconds & $8045-45$ & 18 & 14 \\
\hline 81 & NETSIM & Mean queue discharge headway & 14 & 99 & Tenths of seconds & $8046-46$ & 26 & 34 \\
\hline 82 & NETSIM & Mean queue discharge headway & 14 & 99 & Tenths of seconds & $8048-48$ & 26 & 76 \\
\hline 83 & NETSIM & Mean queue discharge headway & 14 & 99 & Tenths of seconds & $8050-50$ & 26 & 93 \\
\hline 84 & NETSIM & Mean queue discharge headway & 14 & 99 & Tenths of seconds & $8051-51$ & 40 & 38 \\
\hline 85 & NETSIM & Mean queue discharge headway & 14 & 99 & Tenths of seconds & $20-17$ & 40 & 24 \\
\hline 86 & NETSIM & Mean queue discharge headway & 14 & 99 & Tenths of seconds & $54-28$ & 48 & 52 \\
\hline 87 & NETSIM & Mean queue discharge headway & 14 & 99 & Tenths of seconds & $9-8$ & 48 & 18 \\
\hline 88 & NETSIM & Mean queue discharge headway & 14 & 99 & Tenths of seconds & $8-9$ & 40 & 32 \\
\hline 89 & NETSIM & Mean value of start-up lost time & 0 & 99 & Tenths of seconds & $1-26$ & 40 & 46 \\
\hline 90 & NETSIM & Mean value of start-up lost time & 0 & 99 & Tenths of seconds & $1-41$ & 42 & 20 \\
\hline 91 & NETSIM & Mean value of start-up lost time & 0 & 99 & Tenths of seconds & $2-38$ & 40 & 26 \\
\hline 92 & NETSIM & Mean value of start-up lost time & 0 & 99 & Tenths of seconds & $3-27$ & 42 & 40 \\
\hline 93 & NETSIM & Mean value of start-up lost time & 0 & 99 & Tenths of seconds & $4-33$ & 42 & 93 \\
\hline 94 & NETSIM & Mean value of start-up lost time & 0 & 99 & Tenths of seconds & $4-35$ & 42 & 40 \\
\hline 95 & NETSIM & Mean value of start-up lost time & 0 & 99 & Tenths of seconds & $5-42$ & 42 & 26 \\
\hline 96 & NETSIM & Mean value of start-up lost time & 0 & 99 & Tenths of seconds & $6-48$ & 38 & 20 \\
\hline 97 & NETSIM & Mean value of start-up lost time & 0 & 99 & Tenths of seconds & $7-19$ & 40 & 52 \\
\hline 98 & NETSIM & Mean value of start-up lost time & 0 & 99 & Tenths of seconds & $8-21$ & 40 & 42 \\
\hline 99 & NETSIM & Mean value of start-up lost time & 0 & 99 & Tenths of seconds & $9-25$ & 38 & 40 \\
\hline 100 & NETSIM & Mean value of start-up lost time & 0 & 99 & Tenths of seconds & $10-31$ & 38 & 37 \\
\hline 101 & NETSIM & Mean value of start-up lost time & 0 & 99 & Tenths of seconds & $13-39$ & 42 & 50 \\
\hline 102 & NETSIM & Mean value of start-up lost time & 0 & 99 & Tenths of seconds & $13-40$ & 40 & 92 \\
\hline 103 & NETSIM & Mean value of start-up lost time & 0 & 99 & Tenths of seconds & $14-43$ & 20 & 81 \\
\hline
\end{tabular}


TABle 7: Continued.

\begin{tabular}{|c|c|c|c|c|c|c|c|c|}
\hline SN & Model & Parameter & $\begin{array}{l}\text { Lower } \\
\text { bound }\end{array}$ & $\begin{array}{l}\text { Upper } \\
\text { bound }\end{array}$ & Units & Links & $\begin{array}{c}\text { Value } \\
\text { before } \\
\text { calibration }\end{array}$ & $\begin{array}{l}\text { Value after } \\
\text { calibration }\end{array}$ \\
\hline 104 & NETSIM & Mean value of start-up lost time & 0 & 99 & Tenths of seconds & $14-44$ & 20 & 60 \\
\hline 105 & NETSIM & Mean value of start-up lost time & 0 & 99 & Tenths of seconds & $15-47$ & 21 & 15 \\
\hline 106 & NETSIM & Mean value of start-up lost time & 0 & 99 & Tenths of seconds & $16-49$ & 20 & 43 \\
\hline 107 & NETSIM & Mean value of start-up lost time & 0 & 99 & Tenths of seconds & $16-51$ & 20 & 71 \\
\hline 108 & NETSIM & Mean value of start-up lost time & 0 & 99 & Tenths of seconds & $22-45$ & 20 & 20 \\
\hline 109 & NETSIM & Mean value of start-up lost time & 0 & 99 & Tenths of seconds & $11-10$ & 21 & 34 \\
\hline 110 & NETSIM & Mean value of start-up lost time & 0 & 99 & Tenths of seconds & $2-3$ & 21 & 20 \\
\hline 111 & NETSIM & Mean value of start-up lost time & 0 & 99 & Tenths of seconds & $11-12$ & 22 & 13 \\
\hline 112 & NETSIM & Mean value of start-up lost time & 0 & 99 & Tenths of seconds & $12-11$ & 21 & 72 \\
\hline 113 & NETSIM & Mean value of start-up lost time & 0 & 99 & Tenths of seconds & $5-6$ & 28 & 38 \\
\hline 114 & NETSIM & Mean value of start-up lost time & 0 & 99 & Tenths of seconds & $12-13$ & 35 & 27 \\
\hline 115 & NETSIM & Mean value of start-up lost time & 0 & 99 & Tenths of seconds & $13-12$ & 30 & 39 \\
\hline 116 & NETSIM & Mean value of start-up lost time & 0 & 99 & Tenths of seconds & $6-5$ & 30 & 27 \\
\hline 117 & NETSIM & Mean value of start-up lost time & 0 & 99 & Tenths of seconds & $13-14$ & 30 & 29 \\
\hline 118 & NETSIM & Mean value of start-up lost time & 0 & 99 & Tenths of seconds & $14-15$ & 32 & 33 \\
\hline 119 & NETSIM & Mean value of start-up lost time & 0 & 99 & Tenths of seconds & $15-14$ & 28 & 70 \\
\hline 120 & NETSIM & Mean value of start-up lost time & 0 & 99 & Tenths of seconds & $3-4$ & 35 & 33 \\
\hline 121 & NETSIM & Mean value of start-up lost time & 0 & 99 & Tenths of seconds & $51-16$ & 30 & 63 \\
\hline 122 & NETSIM & Mean value of start-up lost time & 0 & 99 & Tenths of seconds & $17-1$ & 42 & 47 \\
\hline 123 & NETSIM & Mean value of start-up lost time & 0 & 99 & Tenths of seconds & $20-2$ & 45 & 50 \\
\hline 124 & NETSIM & Mean value of start-up lost time & 0 & 99 & Tenths of seconds & $43-14$ & 42 & 44 \\
\hline 125 & NETSIM & Mean value of start-up lost time & 0 & 99 & Tenths of seconds & $21-8$ & 40 & 25 \\
\hline 126 & NETSIM & Mean value of start-up lost time & 0 & 99 & Tenths of seconds & $22-1$ & 42 & 49 \\
\hline 127 & NETSIM & Mean value of start-up lost time & 0 & 99 & Tenths of seconds & $23-8$ & 46 & 36 \\
\hline 128 & NETSIM & Mean value of start-up lost time & 0 & 99 & Tenths of seconds & $44-14$ & 40 & 1 \\
\hline 129 & NETSIM & Mean value of start-up lost time & 0 & 99 & Tenths of seconds & $24-9$ & 40 & 81 \\
\hline 130 & NETSIM & Mean value of start-up lost time & 0 & 99 & Tenths of seconds & $52-5$ & 38 & 2 \\
\hline 131 & NETSIM & Mean value of start-up lost time & 0 & 99 & Tenths of seconds & $26-1$ & 40 & 31 \\
\hline 132 & NETSIM & Mean value of start-up lost time & 0 & 99 & Tenths of seconds & $30-9$ & 42 & 13 \\
\hline 133 & NETSIM & Mean value of start-up lost time & 0 & 99 & Tenths of seconds & $30-10$ & 42 & 76 \\
\hline 134 & NETSIM & Mean value of start-up lost time & 0 & 99 & Tenths of seconds & $33-4$ & 46 & 52 \\
\hline 135 & NETSIM & Mean value of start-up lost time & 0 & 99 & Tenths of seconds & $28-15$ & 18 & 6 \\
\hline 136 & NETSIM & Mean value of start-up lost time & 0 & 99 & Tenths of seconds & $35-4$ & 20 & 16 \\
\hline 137 & NETSIM & Mean value of start-up lost time & 0 & 99 & Tenths of seconds & $54-16$ & 20 & 14 \\
\hline 138 & NETSIM & Mean value of start-up lost time & 0 & 99 & Tenths of seconds & $49-16$ & 18 & 4 \\
\hline 139 & NETSIM & Mean value of start-up lost time & 0 & 99 & Tenths of seconds & $55-7$ & 20 & 23 \\
\hline 140 & NETSIM & Mean value of start-up lost time & 0 & 99 & Tenths of seconds & $40-13$ & 25 & 19 \\
\hline 141 & NETSIM & Mean value of start-up lost time & 0 & 99 & Tenths of seconds & $41-1$ & 30 & 89 \\
\hline 142 & NETSIM & Mean value of start-up lost time & 0 & 99 & Tenths of seconds & $55-8$ & 32 & 24 \\
\hline 143 & NETSIM & Mean value of start-up lost time & 0 & 99 & Tenths of seconds & $27-3$ & 32 & 26 \\
\hline 144 & NETSIM & Mean value of start-up lost time & 0 & 99 & Tenths of seconds & $4-52$ & 30 & 34 \\
\hline 145 & NETSIM & Mean value of start-up lost time & 0 & 99 & Tenths of seconds & $31-10$ & 30 & 47 \\
\hline 146 & NETSIM & Mean value of start-up lost time & 0 & 99 & Tenths of seconds & $17-20$ & 30 & 90 \\
\hline 147 & NETSIM & Mean value of start-up lost time & 0 & 99 & Tenths of seconds & $2-20$ & 30 & 34 \\
\hline 148 & NETSIM & Mean value of start-up lost time & 0 & 99 & Tenths of seconds & $34-11$ & 30 & 34 \\
\hline 149 & NETSIM & Mean value of start-up lost time & 0 & 99 & Tenths of seconds & $28-54$ & 40 & 50 \\
\hline 150 & NETSIM & Mean value of start-up lost time & 0 & 99 & Tenths of seconds & $16-54$ & 42 & 44 \\
\hline 151 & NETSIM & Mean value of start-up lost time & 0 & 99 & Tenths of seconds & $7-55$ & 48 & 29 \\
\hline 152 & NETSIM & Mean value of start-up lost time & 0 & 99 & Tenths of seconds & $38-2$ & 42 & 30 \\
\hline 153 & NETSIM & Mean value of start-up lost time & 0 & 99 & Tenths of seconds & $8-55$ & 42 & 0 \\
\hline 154 & NETSIM & Mean value of start-up lost time & 0 & 99 & Tenths of seconds & $25-9$ & 42 & 44 \\
\hline 155 & NETSIM & Mean value of start-up lost time & 0 & 99 & Tenths of seconds & 8018-18 & 40 & 38 \\
\hline 156 & NETSIM & Mean value of start-up lost time & 0 & 99 & Tenths of seconds & $8021-21$ & 40 & 42 \\
\hline 157 & NETSIM & Mean value of start-up lost time & 0 & 99 & Tenths of seconds & $8023-23$ & 42 & 99 \\
\hline 158 & NETSIM & Mean value of start-up lost time & 0 & 99 & Tenths of seconds & $8024-24$ & 42 & 38 \\
\hline 159 & NETSIM & Mean value of start-up lost time & 0 & 99 & Tenths of seconds & $8027-27$ & 40 & 40 \\
\hline 160 & NETSIM & Mean value of start-up lost time & 0 & 99 & Tenths of seconds & $8031-31$ & 40 & 70 \\
\hline 161 & NETSIM & Mean value of start-up lost time & 0 & 99 & Tenths of seconds & $8033-33$ & 46 & 40 \\
\hline
\end{tabular}


TABle 7: Continued.

\begin{tabular}{|c|c|c|c|c|c|c|c|c|}
\hline SN & Model & Parameter & $\begin{array}{l}\text { Lower } \\
\text { bound }\end{array}$ & $\begin{array}{l}\text { Upper } \\
\text { bound }\end{array}$ & Units & Links & $\begin{array}{c}\text { Value } \\
\text { before } \\
\text { calibration }\end{array}$ & $\begin{array}{l}\text { Value after } \\
\text { calibration }\end{array}$ \\
\hline 162 & NETSIM & Mean value of start-up lost time & 0 & 99 & Tenths of seconds & $8035-35$ & 40 & 45 \\
\hline 163 & NETSIM & Mean value of start-up lost time & 0 & 99 & Tenths of seconds & $8038-38$ & 40 & 74 \\
\hline 164 & NETSIM & Mean value of start-up lost time & 0 & 99 & Tenths of seconds & 8039-39 & 47 & 92 \\
\hline 165 & NETSIM & Mean value of start-up lost time & 0 & 99 & Tenths of seconds & $8040-40$ & 43 & 51 \\
\hline 166 & NETSIM & Mean value of start-up lost time & 0 & 99 & Tenths of seconds & $8041-41$ & 41 & 33 \\
\hline 167 & NETSIM & Mean value of start-up lost time & 0 & 99 & Tenths of seconds & $8043-43$ & 41 & 64 \\
\hline 168 & NETSIM & Mean value of start-up lost time & 0 & 99 & Tenths of seconds & $8045-45$ & 42 & 42 \\
\hline 169 & NETSIM & Mean value of start-up lost time & 0 & 99 & Tenths of seconds & $8046-46$ & 40 & 10 \\
\hline 170 & NETSIM & Mean value of start-up lost time & 0 & 99 & Tenths of seconds & $8048-48$ & 42 & 23 \\
\hline 171 & NETSIM & Mean value of start-up lost time & 0 & 99 & Tenths of seconds & $8050-50$ & 40 & 48 \\
\hline 172 & NETSIM & Mean value of start-up lost time & 0 & 99 & Tenths of seconds & $8051-51$ & 40 & 50 \\
\hline 173 & NETSIM & Mean value of start-up lost time & 0 & 99 & Tenths of seconds & 20-17 & 42 & 61 \\
\hline 174 & NETSIM & Mean value of start-up lost time & 0 & 99 & Tenths of seconds & $54-28$ & 38 & 24 \\
\hline 175 & NETSIM & Mean value of start-up lost time & 0 & 99 & Tenths of seconds & $9-8$ & 38 & 38 \\
\hline 176 & NETSIM & Mean value of start-up lost time & 0 & 99 & Tenths of seconds & $8-9$ & 32 & 28 \\
\hline 177 & NETSIM & Duration of a lane-change maneuver & 1 & 8 & Seconds & & 2 & 3 \\
\hline 178 & NETSIM & $\begin{array}{l}\text { Mean time for a driver to react to a sudden } \\
\text { deceleration of the lead vehicle }\end{array}$ & 1 & 30 & Tenths of seconds & & 5 & 7 \\
\hline 179 & NETSIM & Minimum deceleration for lane-changing & 1 & 10 & $\begin{array}{l}\text { Feet per second } \\
\text { square }\end{array}$ & & 3 & 3 \\
\hline 180 & NETSIM & $\begin{array}{c}\text { Difference in the maximum and minimum } \\
\text { acceptable deceleration for a mandatory lane } \\
\text { change }\end{array}$ & 5 & 15 & $\begin{array}{l}\text { Feet per second } \\
\text { square }\end{array}$ & & 7 & 15 \\
\hline 181 & NETSIM & $\begin{array}{c}\text { Difference in the maximum and minimum } \\
\text { acceptable deceleration for a discretionary } \\
\text { lane change }\end{array}$ & 5 & 15 & $\begin{array}{l}\text { Feet per second } \\
\text { square }\end{array}$ & & 5 & 5 \\
\hline 182 & NETSIM & Deceleration rate of the lead vehicle & 10 & 15 & $\begin{array}{l}\text { Feet per second } \\
\text { square }\end{array}$ & & 10 & 10 \\
\hline 183 & NETSIM & Deceleration rate of the follower vehicle & 10 & 15 & $\begin{array}{l}\text { Feet per second } \\
\text { square }\end{array}$ & & 10 & 11 \\
\hline 184 & NETSIM & $\begin{array}{l}\text { Driver-type factor used to compute driver } \\
\text { aggressiveness }\end{array}$ & 15 & 50 & N/A & & 20 & 39 \\
\hline 185 & NETSIM & Urgency threshold & 0 & 5 & $\begin{array}{l}\text { Tenths of a second } \\
\text { squared per foot }\end{array}$ & & 1 & 3 \\
\hline 186 & NETSIM & Safety factor $\mathrm{x} 10$ & 6 & 10 & Tenths of units & & 6 & 8 \\
\hline 187 & NETSIM & $\begin{array}{c}\text { Percentage of drivers who cooperate with a } \\
\text { lane changer }\end{array}$ & 10 & 100 & Percentage & & 30 & 60 \\
\hline 188 & NETSIM & $\begin{array}{c}\text { Headway below which all drivers will attempt } \\
\text { to change lanes }\end{array}$ & 1 & 30 & Tenths of seconds & & 15 & 3 \\
\hline 189 & NETSIM & $\begin{array}{l}\text { Headway above which no drivers will } \\
\text { attempt to change lanes }\end{array}$ & 30 & 100 & Tenths of seconds & & 40 & 40 \\
\hline 190 & NETSIM & $\begin{array}{l}\text { Mean longitudinal distance over which } \\
\text { drivers decide to perform one lane change }\end{array}$ & 50 & 2500 & Feet & & 240 & 387 \\
\hline 191 & NETSIM & Acceptable gap for driver type 1 & 15 & 75 & Tenths of seconds & & 45 & 42 \\
\hline 192 & NETSIM & Acceptable gap for driver type 2 & 15 & 75 & Tenths of seconds & & 40 & 67 \\
\hline 193 & NETSIM & Acceptable gap for driver type 3 & 15 & 75 & Tenths of seconds & & 37 & 39 \\
\hline 194 & NETSIM & Acceptable gap for driver type 4 & 15 & 75 & Tenths of seconds & & 34 & 32 \\
\hline 195 & NETSIM & Acceptable gap for driver type 5 & 15 & 75 & Tenths of seconds & & 31 & 17 \\
\hline 196 & NETSIM & Acceptable gap for driver type 6 & 15 & 75 & Tenths of seconds & & 30 & 31 \\
\hline 197 & NETSIM & Acceptable gap for driver type 7 & 15 & 75 & Tenths of seconds & & 27 & 25 \\
\hline 198 & NETSIM & Acceptable gap for driver type 8 & 15 & 75 & Tenths of seconds & & 24 & 42 \\
\hline 199 & NETSIM & Acceptable gap for driver type 9 & 15 & 75 & Tenths of seconds & & 21 & 19 \\
\hline 200 & NETSIM & Acceptable gap for driver type 10 & 15 & 75 & Tenths of seconds & & 16 & 16 \\
\hline 201 & NETSIM & Additional gap time for crossing 1 lane & 10 & 75 & Tenths of seconds & & 10 & 41 \\
\hline 202 & NETSIM & Additional gap time for crossing 2 lanes & 10 & 75 & Tenths of seconds & & 19 & 19 \\
\hline 203 & NETSIM & Additional gap time for crossing 3 lanes & 10 & 75 & Tenths of seconds & & 23 & 25 \\
\hline 204 & NETSIM & Additional gap time for crossing 4 lanes & 10 & 75 & Tenths of seconds & & 28 & 31 \\
\hline 205 & NETSIM & Additional gap time for crossing 5 lanes & 10 & 75 & Tenths of seconds & & 31 & 24 \\
\hline
\end{tabular}


TABle 7: Continued.

\begin{tabular}{|c|c|c|c|c|c|c|c|c|}
\hline SN & Model & Parameter & $\begin{array}{l}\text { Lower } \\
\text { bound }\end{array}$ & $\begin{array}{l}\text { Upper } \\
\text { bound }\end{array}$ & Units & Links & $\begin{array}{c}\text { Value } \\
\text { before } \\
\text { calibration }\end{array}$ & $\begin{array}{l}\text { Value after } \\
\text { calibration }\end{array}$ \\
\hline 206 & NETSIM & Additional gap time for crossing 6 lanes & 10 & 75 & Tenths of seconds & & 35 & 69 \\
\hline 207 & NETSIM & Additional gap time for crossing 7 lanes & 10 & 75 & Tenths of seconds & & 38 & 52 \\
\hline 208 & NETSIM & Additional gap time for crossing 8 lanes & 10 & 75 & Tenths of seconds & & 41 & 61 \\
\hline 209 & NETSIM & Additional gap time for crossing 9 lanes & 10 & 75 & Tenths of seconds & & 44 & 46 \\
\hline 210 & NETSIM & Additional gap time for crossing 10 lanes & 10 & 75 & Tenths of seconds & & 46 & 47 \\
\hline 211 & NETSIM & $\begin{array}{c}\text { Percentage of drivers that know only one } \\
\text { turn movement }\end{array}$ & 0 & 100 & Percentages & & 5 & 22 \\
\hline 212 & NETSIM & $\begin{array}{c}\text { Percentage of drivers that know two turn } \\
\text { movements }\end{array}$ & 0 & 100 & Percentages & & 95 & 78 \\
\hline
\end{tabular}

TABLE 8: Calibration parameters in the first experiment using the McTrans model.

\begin{tabular}{|c|c|c|c|c|c|c|c|c|}
\hline $\mathrm{SN}$ & Model & Parameter & $\begin{array}{l}\text { Lower } \\
\text { bound }\end{array}$ & $\begin{array}{l}\text { Upper } \\
\text { bound }\end{array}$ & Units & Links & $\begin{array}{l}\text { Value before } \\
\text { calibration }\end{array}$ & Value after calibration \\
\hline 1 & NETSIM & Mean queue discharge headway & 14 & 99 & $\begin{array}{l}\text { Tenths of } \\
\text { seconds }\end{array}$ & $8001-9$ & 58 & 37 \\
\hline 2 & NETSIM & Mean queue discharge headway & 14 & 99 & $\begin{array}{l}\text { Tenths of } \\
\text { seconds }\end{array}$ & $1-9$ & 58 & 68 \\
\hline 3 & NETSIM & Mean queue discharge headway & 14 & 99 & $\begin{array}{l}\text { Tenths of } \\
\text { seconds }\end{array}$ & $1-4$ & 58 & 99 \\
\hline 4 & NETSIM & Mean queue discharge headway & 14 & 99 & $\begin{array}{l}\text { Tenths of } \\
\text { seconds }\end{array}$ & $4-1$ & 58 & 14 \\
\hline 5 & NETSIM & Mean queue discharge headway & 14 & 99 & $\begin{array}{l}\text { Tenths of } \\
\text { seconds }\end{array}$ & $3-1$ & 58 & 73 \\
\hline 6 & NETSIM & Mean queue discharge headway & 14 & 99 & $\begin{array}{l}\text { Tenths of } \\
\text { seconds }\end{array}$ & $1-2$ & 58 & 80 \\
\hline 7 & NETSIM & Mean queue discharge headway & 14 & 99 & $\begin{array}{l}\text { Tenths of } \\
\text { seconds }\end{array}$ & $2-1$ & 58 & 38 \\
\hline 8 & NETSIM & Mean queue discharge headway & 14 & 99 & $\begin{array}{l}\text { Tenths of } \\
\text { seconds }\end{array}$ & $7-2$ & 68 & 45 \\
\hline 9 & NETSIM & Mean queue discharge headway & 14 & 99 & $\begin{array}{l}\text { Tenths of } \\
\text { seconds }\end{array}$ & $8004-7$ & 68 & 69 \\
\hline 10 & NETSIM & Mean queue discharge headway & 14 & 99 & $\begin{array}{l}\text { Tenths of } \\
\text { seconds }\end{array}$ & $6-2$ & 68 & 26 \\
\hline 11 & NETSIM & Mean queue discharge headway & 14 & 99 & $\begin{array}{l}\text { Tenths of } \\
\text { seconds }\end{array}$ & $2-6$ & 68 & 46 \\
\hline 12 & NETSIM & Mean queue discharge headway & 14 & 99 & $\begin{array}{l}\text { Tenths of } \\
\text { seconds }\end{array}$ & $2-5$ & 68 & 89 \\
\hline 13 & NETSIM & Mean queue discharge headway & 14 & 99 & $\begin{array}{l}\text { Tenths of } \\
\text { seconds }\end{array}$ & $5-2$ & 68 & 14 \\
\hline 14 & NETSIM & Mean queue discharge headway & 14 & 99 & $\begin{array}{l}\text { Tenths of } \\
\text { seconds }\end{array}$ & $8006-5$ & 68 & 72 \\
\hline 15 & NETSIM & Mean value of start-up lost time & 0 & 99 & $\begin{array}{l}\text { Tenths of } \\
\text { seconds }\end{array}$ & $8001-9$ & 40 & 59 \\
\hline 16 & NETSIM & Mean value of start-up lost time & 0 & 99 & $\begin{array}{l}\text { Tenths of } \\
\text { seconds }\end{array}$ & $1-9$ & 40 & 42 \\
\hline 17 & NETSIM & Mean value of start-up lost time & 0 & 99 & $\begin{array}{l}\text { Tenths of } \\
\text { seconds }\end{array}$ & $1-4$ & 40 & 86 \\
\hline 18 & NETSIM & Mean value of start-up lost time & 0 & 99 & $\begin{array}{l}\text { Tenths of } \\
\text { seconds }\end{array}$ & $4-1$ & 40 & 17 \\
\hline 19 & NETSIM & Mean value of start-up lost time & 0 & 99 & $\begin{array}{l}\text { Tenths of } \\
\text { seconds }\end{array}$ & $3-1$ & 40 & 65 \\
\hline 20 & NETSIM & Mean value of start-up lost time & 0 & 99 & $\begin{array}{l}\text { Tenths of } \\
\text { seconds }\end{array}$ & $1-2$ & 50 & 43 \\
\hline 21 & NETSIM & Mean value of start-up lost time & 0 & 99 & $\begin{array}{l}\text { Tenths of } \\
\text { seconds }\end{array}$ & $2-1$ & 50 & 35 \\
\hline 22 & NETSIM & Mean value of start-up lost time & 0 & 99 & $\begin{array}{l}\text { Tenths of } \\
\text { seconds }\end{array}$ & $7-2$ & 50 & 80 \\
\hline
\end{tabular}


TABLE 8: Continued.

\begin{tabular}{|c|c|c|c|c|c|c|c|c|}
\hline SN & Model & Parameter & $\begin{array}{l}\text { Lower } \\
\text { bound }\end{array}$ & $\begin{array}{l}\text { Upper } \\
\text { bound }\end{array}$ & Units & Links & $\begin{array}{l}\text { Value before } \\
\text { calibration }\end{array}$ & Value after calibration \\
\hline 23 & NETSIM & Mean value of start-up lost time & 0 & 99 & $\begin{array}{l}\text { Tenths of } \\
\text { seconds }\end{array}$ & $8004-7$ & 50 & 47 \\
\hline 24 & NETSIM & Mean value of start-up lost time & 0 & 99 & $\begin{array}{l}\text { Tenths of } \\
\text { seconds }\end{array}$ & $6-2$ & 50 & 57 \\
\hline 25 & NETSIM & Mean value of start-up lost time & 0 & 99 & $\begin{array}{l}\text { Tenths of } \\
\text { seconds }\end{array}$ & $2-6$ & 50 & 89 \\
\hline 26 & NETSIM & Mean value of start-up lost time & 0 & 99 & $\begin{array}{l}\text { Tenths of } \\
\text { seconds }\end{array}$ & $2-5$ & 50 & 66 \\
\hline 27 & NETSIM & Mean value of start-up lost time & 0 & 99 & $\begin{array}{l}\text { Tenths of } \\
\text { seconds }\end{array}$ & $5-2$ & 50 & 8 \\
\hline 28 & NETSIM & Mean value of start-up lost time & 0 & 99 & $\begin{array}{l}\text { Tenths of } \\
\text { seconds }\end{array}$ & $8006-5$ & 50 & 99 \\
\hline 29 & NETSIM & $\begin{array}{l}\text { Percentage of drivers that know } \\
\text { only one turn movement }\end{array}$ & 0 & 100 & Percentages & & 5 & 79 \\
\hline 30 & NETSIM & $\begin{array}{l}\text { Percentage of drivers that know } \\
\text { two turn movements }\end{array}$ & 0 & 100 & Percentages & & 95 & 21 \\
\hline
\end{tabular}

(i) Set 1 includes all global and local parameters that were selected simultaneously for $70 \%$ of the links

(ii) Set 2 includes global parameters set as default and all local parameters selected for $70 \%$ of the links

(iii) Set 3 includes all global parameters and mean queue discharge headway selected for $70 \%$ of the links

(iv) Set 4 includes all global parameters and mutually exclusive mean queue discharge headway and mean start-up lost time selected at $70 \%$ and $30 \%$ of the links, respectively

As expected, the results show that most of the time, the NRMS decreased with an increased percentage of selected links for calibration. The NRMS value changed for various sets of parameters for the same percentage of links selected for calibration. In both cases, similar values of NRMS between a calibrated and an uncalibrated condition did not suggest that all calibration criteria were met.

\section{Conclusion}

This study proposed a methodology that enables the selection of any combination of facilities as well as local and global parameters for the calibration of microsimulation traffic flow models. A mathematical program and solution algorithm were proposed to implement the methodology. Results using two network models and various sensitivity analyses showed that the proposed methodology was effective. The models were calibrated successfully for volumes and speeds, subject to the selection of a minimum number of links for calibration. The percentage of links selected for calibration varied from a minimum percentage to $100 \%$. Similarly, various local parameters were selected for the corresponding links. Multiple experiments were performed by varying the selection of global and local calibration parameters. Unselected parameters were assigned default values.

The experiments were tested using CORSIM models. However, the methodology was developed without taking into consideration the characteristics of a specific traffic flow simulation model. That is, no information regarding the methods used in CORSIM to propagate flow was used. Future work could involve testing the proposed methodology using other traffic flow simulation models. Similarly, the proposed methodology might be able to provide superior results by means of a multiobjective optimization approach in contrast to the single-objective function used in this study [20].

\section{Appendix}

\section{Calibration Parameters}

Tables 7 and 8 show the calibration parameters used in the first set of experiments using CORSIM models.

\section{Data Availability}

The McTrans model is available at https://mctrans.ce.ufl. edu/mct/index.php/hcs/hcs-downloads/. The Reno network and corresponding data are proprietary and cannot be provided by the authors. The Nevada Department of Transportation can provide access to the model and data.

\section{Disclosure}

This manuscript is based on a thesis by Mr. Kul Shrestha as part of his master's degree in Transportation Engineering from the University of Nevada Las Vegas.

\section{Conflicts of Interest}

The authors declare that they have no conflicts of interest.

\section{Acknowledgments}

Special thanks are due to Mrs. Julie Longo for her help in editing this manuscript. 


\section{References}

[1] R. Dowling, A. Skabardonis, J. Halkias, G. McHale, and G. Zammit, "Guidelines for calibration of microsimulation models: framework and applications," Transportation Research Record: Journal of the Transportation Research Board, vol. 1876, no. 1, pp. 1-9, 2004.

[2] P. Holm, D. Tomich, J. Sloboden, and C. Lowrance, "Traffic analysis toolbox volume IV: guidelines for applying CORSIM microsimulation modeling software," Report No. FHWAHOP-07-079, IV (January), 1-349, ITT Industries, White Plains, NY, USA, 2007, http://trid.trb.org/view.aspx? $\mathrm{id}=838485$.

[3] A. Paz, V. Molano, E. Martinez, C. Gaviria, and C. Arteaga, "Calibration of traffic flow models using a memetic algorithm," Transportation Research Part C: Emerging Technologies, vol. 55, no. 4, pp. 432-443, 2015.

[4] J. Ma, H. Dong, and H. M. Zhang, "Calibration of microsimulation with heuristic optimization methods," Transportation Research Record: Journal of the Transportation Research Board, vol. 1999, no. 1, pp. 208-217, 2007.

[5] M. Jha, G. Gopalan, A. Garms, B. Mahanti, T. Toledo, and M. Ben-Akiva, "Development and calibration of a large-scale microscopic traffic simulation model," Transportation Research Record: Journal of the Transportation Research Board, vol. 1876, no. 1, pp. 121-131, 2004.

[6] A. Paz, V. Molano, and M. Sanchez, "Holistic calibration of microscopic traffic flow models: methodology and real world application studies," Engineering and Applied Sciences Optimization: Dedicated to the memory of Professor M.G. Karlaftis, Springer International Publishing, vol. 38, no. 1, New York, NY, USA, 2015.

[7] K. O. Kim and L. R. Rilett, "Simplex-Based calibration of traffic microsimulation models with intelligent transportation systems data," Transportation Research Record: Journal of the Transportation Research Board, vol. 1855, no. 1, pp. 80-89, 2003.

[8] R.-L. Cheu, X. Jin, K.-C. Ng, Y.-L. Ng, and D. Srinivasan, "Calibration of FRESIM for Singapore expressway using genetic algorithm," Journal of Transportation Engineering, vol. 124, no. 6, pp. 526-535, 1998.

[9] A. L. Cunha, J. E. Bessa Jr., and J. R. Setti, "Genetic algorithm for the calibration of vehicle performance models of microscopic traffic simulators," in Proceedings of the Portuguese Conference on Artificial Intelligence, pp. 3-14, Aveiro, Portugal, October 2009.

[10] K.-O. Kim and L. R. Rilett, "Genetic-algorithm based approach for calibrating microscopic Simulation models," in Proceedings of the Intelligent Transportation Systems 2001, pp. 698-704, Turin, Italy, Febraury 2001.

[11] T. Ma and B. Abdulhai, "Genetic algorithm-based optimization approach and generic tool for calibrating traffic microscopic simulation parameters," Transportation Research Record: Journal of the Transportation Research Board, vol. 1800, no. 1, pp. 6-15, 2002.

[12] B. Park, J. Won, and I. Yun, "Application of microscopic simulation model calibration and validation procedure: case study of coordinated actuated signal system," Transportation Research Record: Journal of the Transportation Research Board, vol. 1978, no. 1, pp. 113-122, 2006.

[13] S. J. Kim, Simultaneous calibration of a Microscopic Traffic Simulation Model and OD matrix, Texas A\&M University, College Station, TX, USA, PhD Diss., 2006.
[14] S. Chiappone, O. Giuffrè, A. Granà, R. Mauro, and A. Sferlazza, "Traffic simulation models calibration using speed-density relationship: an automated procedure based on genetic algorithm," Expert Systems with Applications, vol. 44, pp. 147-155, 2016.

[15] Y. Yang, H. Dong, Y. Qin, and Q. Zhang, "Parameter calibration method of microscopic traffic flow simulation models based on orthogonal genetic algorithm," in Proceedings of the 22nd International Conference on Distributed Multimedia Systems, Colchester, UK, November 2016.

[16] R. Balakrishna, C. Antoniou, M. Ben-Akiva, and H. Koutsopoulos, "Calibration of microscopic traffic simulation models: methods and application," Transportation Research Board: Journal of the Transportation Research Board, vol. 1999, no. 1, pp. 198-207, 2007.

[17] J. B. Lee, Calibration of Traffic Simulation Models Using Simultaneous Perturbation Stochastic Approximation (SPSA) Method Extended through Bayesian Sampling Methodology, Rutgers The State University of New Jersey-New Brunswick, New Brunswick, NJ, USA, 2008.

[18] A. Paz, V. Molano, and C. Gaviria, "Calibration of CORSIM models considering all model parameters simultaneously," in Proceedings of the Intelligent Transportation Systems (ITSC), 2012 15th International IEEE Conference, pp. 1417-1422, Anchorage, AK, USA, September 2012.

[19] A. Paz, V. Molano, and A. Khan, "Calibration of microscopic traffic flow models considering all parameters simultaneously," in Proceedings of the 93rd Annual Meeting of the Transportation Research Board, Washington, DC, USA, January 2014.

[20] C. Cobos, C. Daza, C. Martínez et al., "Calibration of microscopic traffic flow simulation models using a memetic algorithm with Solis and Wets local search chaining (MASW-Chains)," in Proceedings of the Ibero-American Conference on Artificial Intelligence, pp. 365-375, San José, Costa Rica, November 2016.

[21] C. Cobos, C. Erazo, J. Luna et al., "Multi-objective memetic algorithm based on NSGA-II and simulated annealing for calibrating CORSIM micro-simulation models of vehicular traffic flow," in Proceedings of the Conference of the Spanish Association for Artificial Intelligence, pp. 468-476, Salamanca, Spain, September 2016.

[22] C. Cobos, A. Paz, J. Luna, C. Erazo, and M. Mendoza, "A multi-objective approach for the calibration of microscopic traffic flow simulation models," IEEE Access, vol. 8, pp. 103124-103140, 2020.

[23] A. Halati, H. Lieu, and S. Walker, "CORSIM-corridor traffic simulation model," in Proceedings of the Traffic Congestion and Traffic Safety in the 21st Century: Challenges, Innovations, and Opportunities, New York, NY, USA, June 1997.

[24] B. Ciuffo, V. Punzo, and V. Torrieri, "Comparison of simulation-based and model-based calibrations of traffic-flow microsimulation models," Transportation Research Record: Journal of the Transportation Research Board, vol. 2088, no. 1, pp. 36-44, 2008.

[25] V. Punzo and B. Ciuffo, "How parameters of microscopic traffic flow models relate to traffic dynamics in simulation: implications for model calibration," Transportation Research Record: Journal of Transportation Research Board, vol. 2124, no. 1, 2009.

[26] M. Gen and R. Cheng, Genetic Algorithms and Engineering Optimization, Vol. 7, John Wiley \& Sons, Tokyo, Japan, 2000. 
[27] D. E. Goldberg, Genetic Algorithms in Search, Optimization and Machine Learning, Addison-Wesley, Boston, MA, USA, 1989.

[28] W. T. Hung, F. Tian, and H. Y. Tong, "Discharge headway at signalized intersections in Hong Kong," Journal of Advanced Transportation, vol. 37, no. 1, pp. 105-117, 2003. 